\title{
Ruthenium-based olefin metathesis catalysts with monodentate unsymmetrical NHC ligands
}

\author{
Veronica Paradiso, Chiara Costabile and Fabia Grisi
}

\author{
Review \\ Address: \\ Dipartimento di Chimica e Biologia "Adolfo Zambelli", Università di \\ Salerno, Via Giovanni Paolo II 132, I-84084 Fisciano, Salerno, Italy \\ Email: \\ Fabia Grisi ${ }^{*}$ - fgrisi@unisa.it \\ * Corresponding author \\ Keywords: \\ ligand design; olefin metathesis; ruthenium catalysts; selectivity; \\ unsymmetrical $\mathrm{N}$-heterocyclic carbenes
}

Beilstein J. Org. Chem. 2018, 14, 3122-3149.

doi:10.3762/bjoc. 14.292

Received: 01 September 2018

Accepted: 22 November 2018

Published: 28 December 2018

This article is part of the thematic issue "Progress in metathesis chemistry III".

Guest Editors: K. Grela and A. Kajetanowicz

(C) 2018 Paradiso et al.; licensee Beilstein-Institut.

License and terms: see end of document.

\begin{abstract}
An overview on the catalytic properties of ruthenium complexes for olefin metathesis bearing monodentate unsymmetrical $\mathrm{N}$-heterocyclic diaminocarbene ligands is provided. The non-symmetric nature of these NHC architectures strongly influences activity and selectivity of the resulting catalysts. The main achievements that have been accomplished in significant areas of olefin metathesis up to the current state of research are discussed.
\end{abstract}

\section{Introduction}

The transition metal-catalyzed olefin metathesis reaction is an indispensable synthetic tool for the construction of new carbon-carbon double bonds in various applications in both organic and polymer chemistry $[1,2]$. The great popularity of this methodology is mainly related to the development of welldefined ruthenium alkylidene catalysts with high air and moisture stability and functional group tolerance. Among them, ruthenium olefin metathesis complexes bearing N-heterocyclic carbene (NHC) ligands, known as second generation catalysts (Figure 1), have shown improved catalytic efficiency over other metathesis catalysts $[3,4]$.
Moreover, their catalytic properties can be finely modulated through variation of the steric and electronic properties of the NHC ligand. Significant advances in ruthenium metathesis catalyst design have been achieved by the introduction of unsymmetrically substituted NHC (uNHC) ligands, namely presenting different substituents at the nitrogen atoms. They offer the possibility of strongly influencing the reactivity and selectivity of the resulting catalysts by creating different steric and/or electronic environments around the metal center. Indeed, ruthenium complexes coordinated with this kind of ligands can be easily tailored for challenging or specific metathesis applications in 


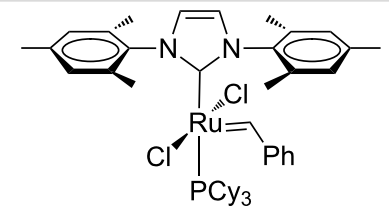

GII-IMes

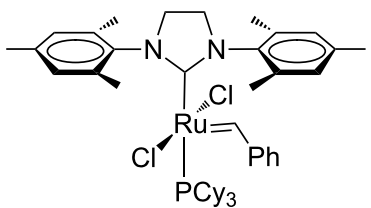

GII-SIMes

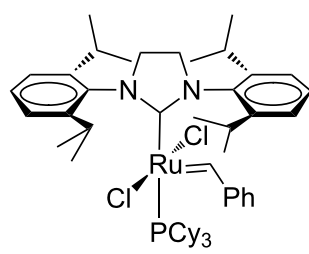

GII-SIPr

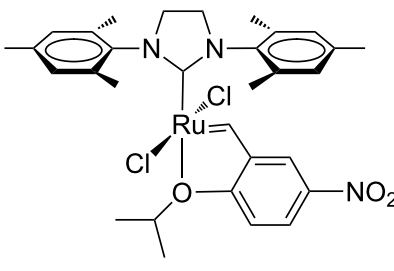

Gre-II

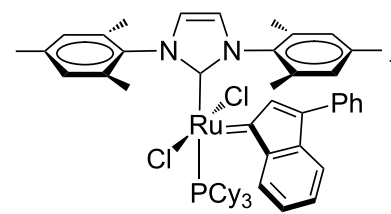

IndII-IMes

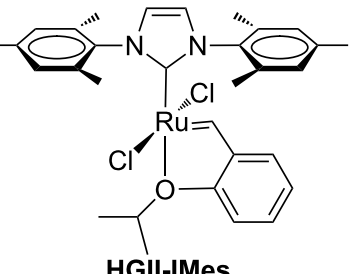

HGII-IMes

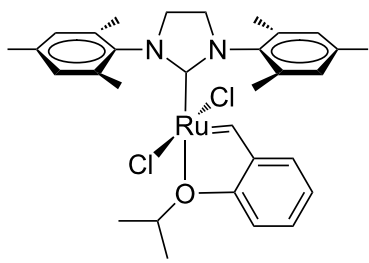

HGII-SIMes

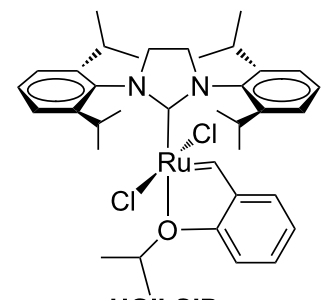

HGII-SIPr

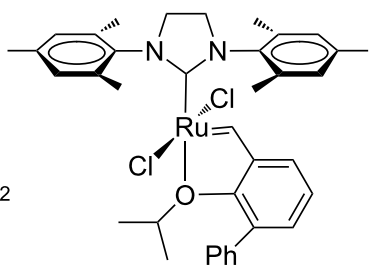

Ble-II

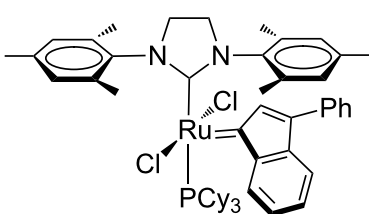

IndII-SIMes

Figure 1: Second-generation Grubbs (GII), Hoveyda (HGII), Grela (Gre-II), Blechert (Ble-II) and indenylidene-type (IndII) catalysts with symmetrical NHCs.

which their symmetrical counterparts fail or show poor efficiency $[5,6]$. Moreover, the use of catalysts incorporating bidentate unsymmetrical NHCs has allowed for significant enhancements in the field of both asymmetric and $Z$-selective olefin metathesis reactions [7-9].

The aim of the present review is to provide a description of the catalytic behavior of ruthenium complexes bearing monodentate five-membered uNHCs. A special focus is given to the more recent advancements in the development of such unsymmetrical architectures for targeted metathesis applications.
Ruthenium complexes with NHCs presenting alternative heteroatoms, such as thiazol-2-ylidene ligands [10], or those containing one nitrogen substituent, such as the series of cyclic (alkyl) (amino) carbenes (CAACs) introduced by Bertrand et al. [11], are not included in this survey.

\section{Review}

\section{Ruthenium catalysts coordinated with $\mathrm{N}$-aryl, $\mathrm{N}^{\prime}$-aryl NHCs}

The first ruthenium complexes with monodentate NHC ligands bearing unsymmetrical $N$-aryl, $N$ '-aryl groups were reported by Blechert [12], who synthesized Grubbs and Hoveyda-type complexes with $N$-phenyl, $N$ '-mesityl NHC substituents $(\mathbf{1 a}, \mathbf{b}$ in Figure 2). Both complexes were air stable, but in $\mathrm{CH}_{2} \mathrm{Cl}_{2}$ solution complex $\mathbf{1 b}$ converted completely within a few hours into complex 2 due to the formation of an intramolecular carbene-arene bond between the benzylidene carbon atom and the ortho position of the $\mathrm{N}$-phenyl ligand (Figure 3). According to the authors, the mechanism of the reaction that occurs only in the presence of oxygen, involves a pericyclic reaction followed by an irreversible oxidation step, and, finally, a rearomatization.

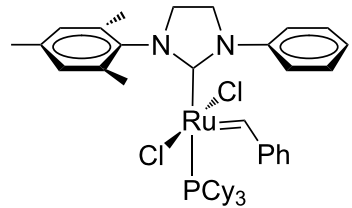

1a

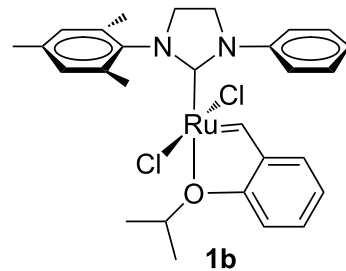

$1 \mathrm{~b}$
Figure 2: Grubbs (1a) and Hoveyda-type (1b) complexes with $N$-phenyl, N'-mesityl NHCs.

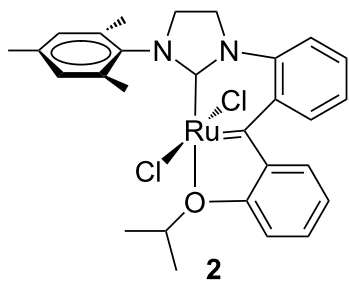

Figure 3: $\mathrm{C}-\mathrm{H}$ insertion product 2.

To avoid the $\mathrm{C}-\mathrm{H}$ activation of aryl-substituted NHC ligands the corresponding ortho positions have to be substituted by different groups. Indeed, almost contemporaneously, Grubbs et al. reported on the synthesis of a family of corresponding orthosubstituted $N$-fluorophenyl, $N$ '-aryl NHC Ru complexes (Figure 4) $[13,14]$. 


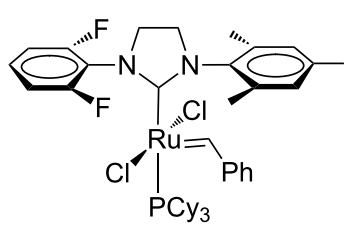

$3 a$

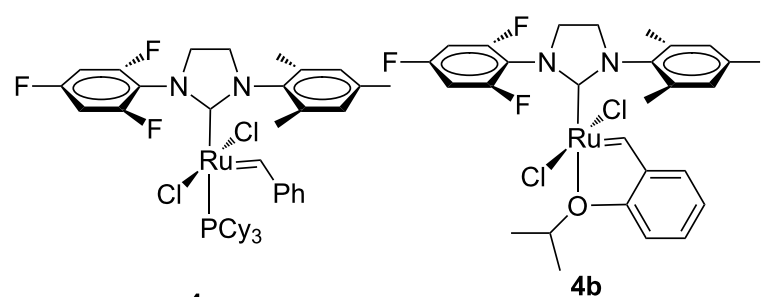

$4 a$

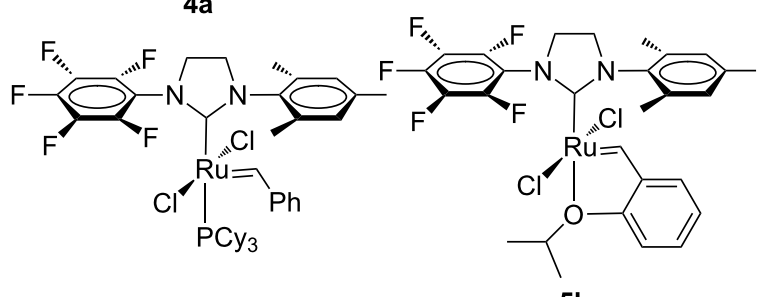

$5 a$

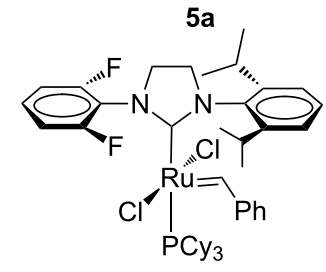

$6 a$

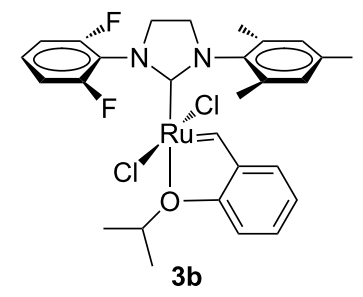

$5 b$

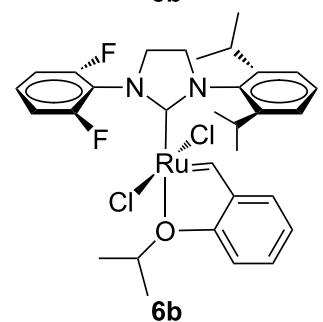

$6 b$
Figure 4: Grubbs (3a-6a) and Hoveyda-type (3b-6b) complexes with $N$-fluorophenyl, $N$ '-aryl NHCs.

The behavior of this catalyst family was tested in the RCM of diethyl diallylmalonate (7, Scheme 1) and compared with that of GII-SIMes and HGII-SIMes.<smiles>C=CCC(CC=C)(CC=C)C(=O)OCC</smiles>

7
$\underset{\mathrm{CD}_{2} \mathrm{Cl}_{2}, 30^{\circ} \mathrm{C}}{\stackrel{\mathrm{mol} \%[\mathrm{Ru}]}{\longrightarrow}}$

$0.1 \mathrm{M}$

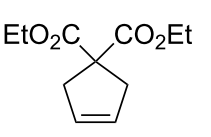

8
Scheme 1: RCM of diethyl diallylmalonate (7).

Interestingly, catalysts $\mathbf{3 a}$ and $\mathbf{4 a}$ clearly outperformed GIISIMes, with catalyst $\mathbf{4 a}$ emerging as the most efficient of all ( $>97 \%$ conversion in $9 \mathrm{~min}$ ). Complex 5a showed a higher initiation rate with respect to GII-SIMes, but eventually was found to be less efficient due to a decrease in its catalytic activity related to concomitant decomposition. As for Hoveyda-type catalysts $\mathbf{3 b}, \mathbf{4 b}$ and $\mathbf{5 b}$, they all disclosed lower activity than the parent complex HGII-SIMes, with catalyst $\mathbf{5 b}$ being the least efficient of all in this series ( $>97 \%$ conversion in $100 \mathrm{~min}$ ). Finally, 6a as well as the phosphine-free $\mathbf{6 b}$ showed to be very poor olefin metathesis catalysts.

Enhanced catalytic performances, with respect to GII-SIMes, were previously reported also for symmetrical NHC bearing $o$-fluorinated aryl groups. Possibly the presence of a $\mathrm{Ru}-\mathrm{F}$ interaction is responsible for the positive impact on the reaction rates [15]. Similar results were observed in the RCM of the more hindered diethyl allylmethallylmalonate (9, Scheme 2), where 3a and 4a behaved as the most efficient catalysts.

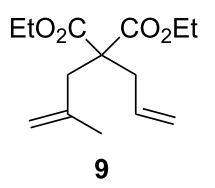

$$
\begin{gathered}
\underset{0.1 \mathrm{Mol} \%[\mathrm{Ru}]}{\stackrel{1 \mathrm{M}}{\mathrm{CD}_{2} \mathrm{Cl}_{2}, 30{ }^{\circ} \mathrm{C}}} \\
0 .
\end{gathered}
$$<smiles>CCOC(=O)C1(C(=O)OCC)CC=C(C)C1</smiles>

Scheme 2: RCM of diethyl allylmethallylmalonate (9).

Even in the challenging formation of tetrasubstituted olefin $\mathbf{1 2}$ via RCM (Scheme 3), catalysts 3a and 4a gave the best performances leading to $30 \%$ and $21 \%$ conversion, respectively, in four days.<smiles>C=C1CC(=C)CC(C(=O)OCC)(C(=O)OCC)C1</smiles>

11

$$
\underset{\mathrm{CD}_{2} \mathrm{Cl}_{2}, 30^{\circ} \mathrm{C}}{\stackrel{5 \mathrm{~mol} \%[\mathrm{Ru}]}{\longrightarrow}}
$$$$
0.1 \mathrm{M}
$$

$0.1 \mathrm{M}$
Scheme 3: RCM of diethyl dimethallylmalonate (11).

In the CM of allylbenzene (13) with cis-1,4-diacetoxy-2-butene (14, Scheme 4), the fluorinated complexes $\mathbf{3 a}-\mathbf{5 a}$ and $\mathbf{3 b}-\mathbf{5 b}$ exhibited activities comparable to GII-SIMes and HGIISIMes, showing higher $Z$-selectivity at conversions above $60 \%$. For example, catalyst GII-SIMes affords an $E / Z$ ratio of $\sim 10$ at $79 \%$ conversion, whereas catalysts $3-5$ gave an $E / Z$ ratio of about 5.5 at the same conversion.

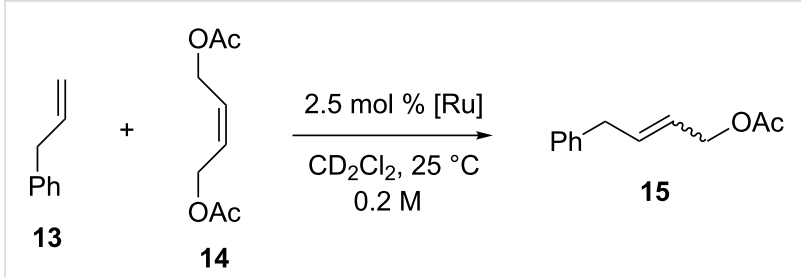

Scheme 4: CM of allylbenzene (13) with cis-1,4-diacetoxy-2-butene (14). 
As for the ROMP of 16 (Scheme 5), GII-SIMes and 4a displayed the highest activity with similar reactivity.

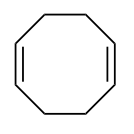

16

$$
\begin{gathered}
\underset{\mathrm{CD}_{2} \mathrm{Cl}_{2}, 30{ }^{\circ} \mathrm{C}}{0.1 \mathrm{~mol} \%[\mathrm{Ru}]} \\
0.5 \mathrm{M}
\end{gathered}
$$<smiles>C=CCCCC(C)(C)C</smiles>

17
Scheme 5: ROMP of 1,5-cyclooctadiene (16).

In the attempt to rationalize the catalytic performances of this family of $N$-fluorophenyl complexes the related $\left[\mathrm{Rh}(\mathrm{CO})_{2} \mathrm{Cl}(\mathrm{NHC})\right]$ complexes were synthesized. Unfortunately the shifts of the $\mathrm{CO}$ stretching frequencies showed that no correlation between the catalytic performances of Ru-cata- lysts and electronic properties of the corresponding NHC ligand is found.

More recently, Osypov and co-workers introduced a new family of Grubbs (18a-21a) and Hoveyda-type (18b-21b) catalysts bearing unsymmetrical NHC ligands with one of the $N$-aryl substituents presenting a hexafluoroisopropylalkoxy $\left[\left(\mathrm{CF}_{3}\right)_{2}(\mathrm{OR})-\mathrm{C}\right]$ group (Figure 5) [16,17].

Catalysts 18a and 19a showed efficiencies comparable to GIISIMes and HGII-SIMes in the RCM of substrate 7 (Scheme 1), giving full conversion within 30 minutes, whereas the corresponding Hoveyda-type complexes $\mathbf{1 8 b}$ and $19 \mathrm{~b}$ presented a more pronounced initiation period, giving good conversions in much longer reaction time (2-4 h) [16]. A similar trend was observed in the RCM of 9 (Scheme 2), but reaction rates were lower in all cases. As for 20a and 21a, the initiation rates in the

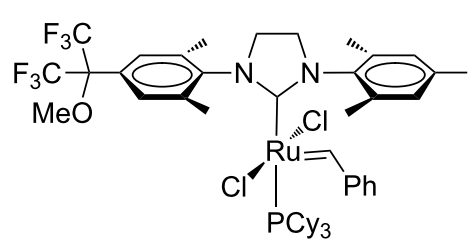

$18 a$

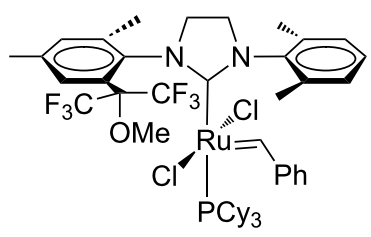

$19 a$

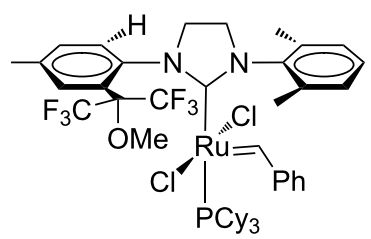

$20 a$

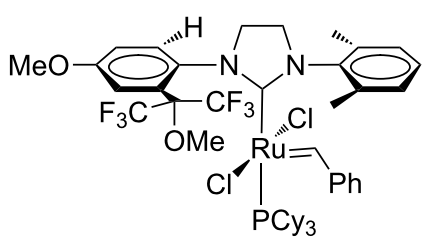

$21 a$
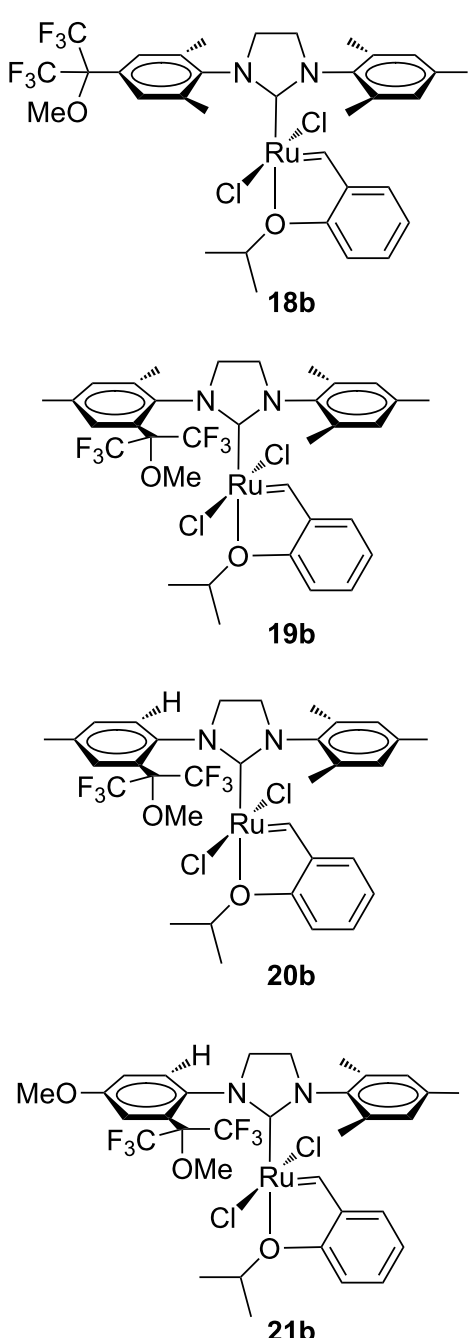

Figure 5: Grubbs (18a-21a) and Hoveyda-type (18b-21b) catalysts bearing uNHCs with a hexafluoroisopropylalkoxy $\left[\left(\mathrm{CF}_{3}\right)_{2}(\mathrm{OR})-\mathrm{C}\right]$ group in one of the $\mathrm{N}$-aryl substituents. 
RCM of 7 were observed to be faster than GII-SIMes, HGIISIMes and 19a, while the initiation rates of $20 \mathrm{~b}$ and $\mathbf{2 1 b}$ were lower than GII-SIMes and HGII-SIMes, but superior to $\mathbf{1 9 b}$, resulting in $90 \%$ conversion within 3 hours [17]. No relevant differences in the catalyst reactivity were observed for the $\mathrm{CM}$ of $\mathbf{1 3}$ and $\mathbf{1 4}$ (Scheme 4).

As a novel application of $N$-aryl, $N^{\prime}$-aryl unsymmetrical ruthenium complexes in enantioselective catalysis, Grela and Schmidt very recently reported on the first example of a helically chiral Hoveyda-type metathesis complex. This catalyst, bearing a mesityl and a helicene as the aryl groups, was preliminary examined in some model asymmetric metathesis transformations and showed promising levels of enantioselectivity. Further studies on the development of this new concept for enantioinduction are still ongoing [18].

\section{Ruthenium catalysts coordinated with $N$-alkyl, N'-aryl NHCs}

\section{$\mathrm{N}$-Alkyl-substituents possessing no functionalities or} heteroatoms

Unsymmetrical $N$-alkyl, $N^{\prime}$-aryl NHC frameworks were initially developed in order to improve the catalytic activity of ruthenium-based complexes through enhanced electron-donating ability and different steric bulk of the NHC ligand. Mol et al. introduced complex 22 (Figure 6) in which one of the mesityl groups from GII-SIMes was replaced by the sterically more encumbered adamantyl group [19].

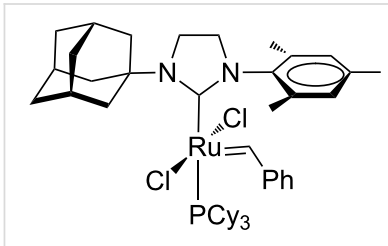

22

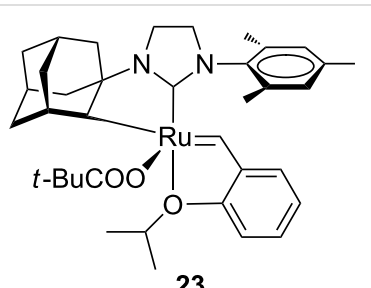

23
Figure 6: A Grubbs-type complex with an $N$-adamantyl, $N$ '-mesityl $\mathrm{NHC} 22$ and the Hoveyda-type complex with a chelating $N$-adamantyl, N'-mesityl NHC 23

However, no beneficial effect on the catalytic activity was observed. Indeed complex 22 revealed a very poor olefin metathesis catalyst, likely as a consequence of the excessive steric hindrance of the adamantyl moiety at the ruthenium center. It is worth to underline that the first $Z$-selective ruthenium catalyst (23, Figure 6), developed by Grubbs and co-workers, is based on a chelating NHC ligand that is derived from an intramolecular carboxylate-driven $\mathrm{C}-\mathrm{H}$ bond insertion of the adamantyl $\mathrm{N}$-substituent of the same NHC ligand in complex 22 [20]. Unsymmetrical complexes bearing smaller $N$-alkyl groups (Figure 7) were reported by Blechert and co-workers [21].

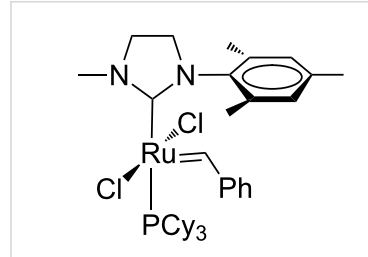

$24 a$

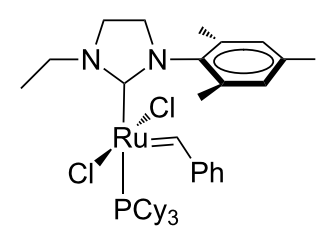

$25 a$
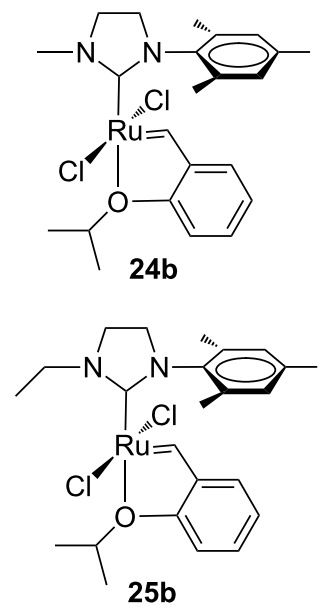

Figure 7: Grubbs (24a and 25a) and Hoveyda-type (24b and 25b) complexes with $\mathrm{N}$-alkyl, $N$ '-mesityl NHCs.

In addition to the concept that the presence of more electron-donating alkyl groups on the NHC could lead to enhanced $\sigma$-donor properties, and, consequently, to higher catalytic activity, the authors postulated that the unsymmetrical nature of the NHC ligands could improve $E / Z$ selectivity in $C M$ reactions and diastereoselectivity in RCM reactions altering the environment of key metathesis intermediates. Complexes $\mathbf{2 4}$ and $\mathbf{2 5}$ were found to exist in solution as a single rotational isomer having the benzylidene moiety located under the mesityl group, and for complexes $\mathbf{2 4 b}$ and $\mathbf{2 5 b}$ this orientation was observed also in the solid state. Some metathesis reactions performed in this study with 24b and 25b in comparison to GII-SIMes and HGII-SIMes are summarized in Table 1. In the model RCM reaction of $N, N$-diallyl- $p$-toluenesulfonamide (26, Table 1, entry 1), catalysts $24 \mathbf{a}$ and $24 \mathbf{b}$ showed activities similar to that of GII-SIMes. They also exhibited different $E / Z$ selectivities in CM transformations (e.g., Table 1, entry 2), and gave improved selectivities in a diastereoselective RCM reaction (Table 1, entry 3).

Ledoux, Verpoort et al. described a series of phosphine-containing unsymmetrical catalysts 31-34 characterized by alkyl $\mathrm{N}$-substituents with variable steric bulk (Figure 8) [22].

The catalytic performances of these complexes and of complex 24a were evaluated for the RCM of diethyl diallylmalonate (7) and the ROMP of cis-1,5-cyclooctadiene (16). In the RCM reaction (Scheme 1), performed at $20{ }^{\circ} \mathrm{C}$ in $\mathrm{CD}_{2} \mathrm{Cl}_{2}$ at a catalyst concentration of $4.52 \mathrm{mM}$ and a substrate/catalyst ratio of 200 ( $0.5 \mathrm{~mol} \%$ of catalyst), a strong dependence of the catalytic activities on the steric bulkiness of the $N$-alkyl substituents was observed. Indeed, an increase in the size of the alkyl group resulted in a lower catalyst activity. Indeed, complex $\mathbf{2 4 a}$ bear- 


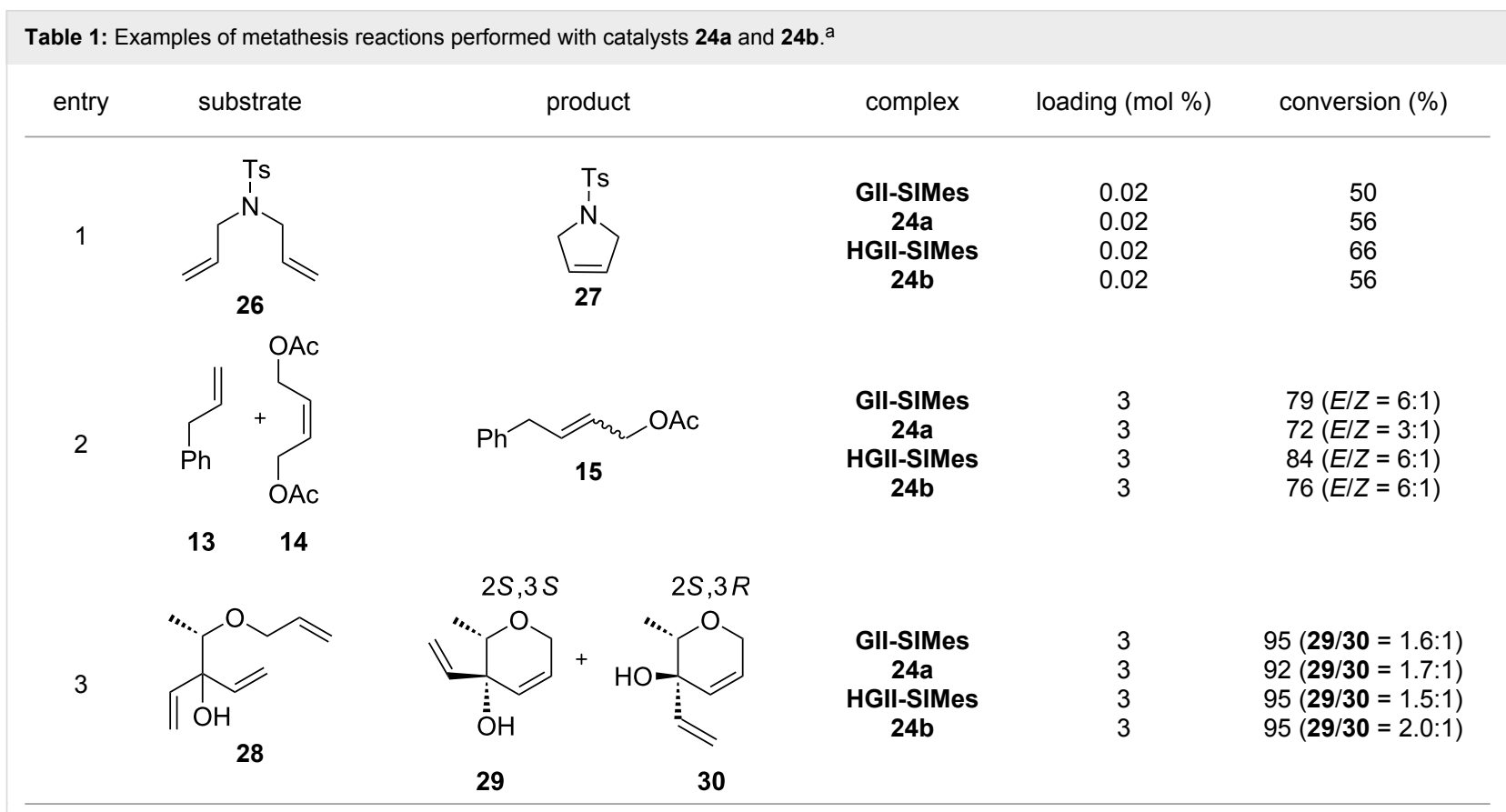

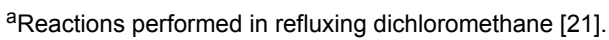

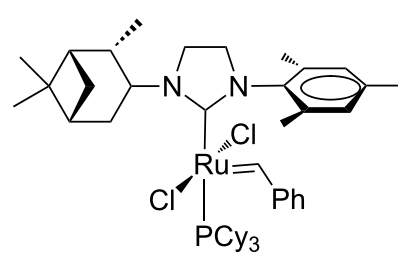

31

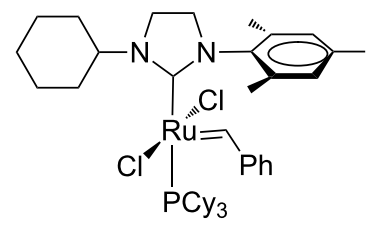

33<smiles>Cc1cc(C)c(N2CCN(C(C)(C)C)C2[R](Cl)(Cl)C=P)c(C)c1</smiles>

32<smiles>CCCCCCCCN1CCN(c2c(C)cc(C)cc2C)C1[R](Cl)(Cl)C=P</smiles>

34

Figure 8: Grubbs-type complexes 31-34 with N-alkyl, N'-mesityl NHCs.

ing the small methyl moiety on the nitrogen, revealed as the best performing catalyst, even surpassing the parent complex GII-SIMes. In the ROMP reaction (Scheme 5), carried out in different solvents and monomer/catalyst ratios, the activities of complexes 31, 33 and $\mathbf{3 4}$ were superior to that of the symmetrical counterpart GII-SIMes at low COD/catalyst loading in $\mathrm{CDCl}_{3}$. In general, the complexes were less dependent on the solvent used with respect to GII-SIMes. Catalyst 32, having a bulky $N$-tert-butyl substituent on the NHC, displayed a consid- erably lower activity than the other tested catalysts. The replacement of the mesityl group by a 2,6-diisopropylphenyl group as in complexes 24a and $\mathbf{3 3}$ led preferentially to bis(NHC)-coordinated complexes, which showed metathesis activity only at elevated temperatures [23]. However, the mono(NHC) complex 35 (Figure 9) was isolated and tested in the RCM of 7 and the ROMP of cis-1,5-cyclooctadiene (16), where it displayed a fair olefin metathesis activity compared to the benchmark catalyst GII-SIMes [23]. 


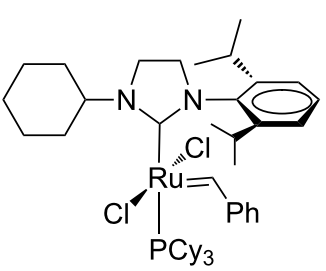

35

Figure 9: Grubbs-type complex 35 with an N-cyclohexyl, N'-2,6-diisopropylphenyl NHC

Studies on this class of unsymmetrical NHC ligands were also extended to the Hoveyda-type complexes 36-40 (Figure 10) [24]. The effect of the modified NHC ligand was investigated in model metathesis reactions ( $\mathrm{RCM}$ of 7, ROMP of 16 and $\mathrm{CM}$ of 13 with acrylonitrile) in comparison to complex $24 \mathbf{b}$ and the parent complexes GII-SIMes and GII-SIPr.

No real improvement in the catalytic activity was observed in any of the tested metathesis reactions, while different $E / Z$ selectivities were observed in the CM of allylbenzene (13) with acrylonitrile. These results underline that steric differences in $\mathrm{N}$-alkyl NHC ligands are more important than differences in their donor capacities in determining the activity and selectivity of the corresponding catalysts.

Quite recently, on the basis of a previous work, Verpoort et al. reported on the synthesis and characterization of second generation ruthenium indenylidene catalysts bearing $N$-alkyl, $N$ '-mesityl-substituted NHCs $\mathbf{4 1 - 4 3}$ in which the alkyl group was methyl (41), octyl (42) or cyclohexyl (43, Figure 11) [25].

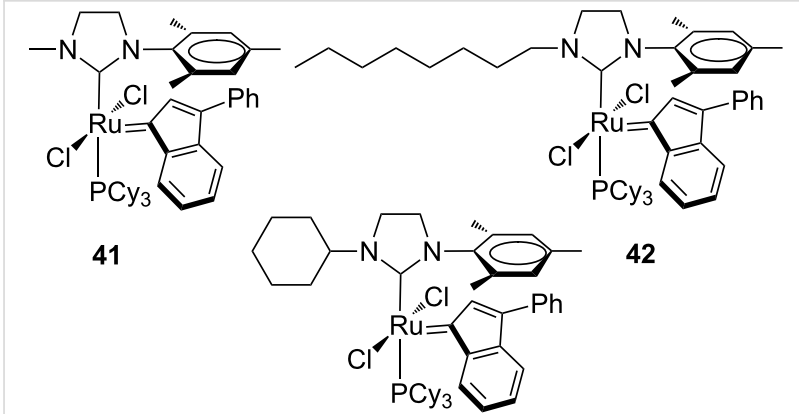

43

Figure 11: Indenylidene-type complexes 41-43 with $N$-alkyl, $N$ '-mesityl NHCs.

For all of the complexes, two rotamers were observed in solution, and the most abundant species was identified as the isomer with the indenylidene moiety located under the mesityl group. Solid-state structures of the complexes showed, consistently, the same relative orientation between the indenylidene and mesityl unit. Complexes 41-43 were tested in various representative metathesis reactions of standard substrates and compared to the benchmark catalysts IndII-SIMes. Interestingly, all complexes showed a faster catalytic initiation than IndII-SIMes. This faster initiation may be due to the stronger $\sigma$-donating properties of the unsymmetrical $\mathrm{N}$-alkyl-substituted NHC ligands. Catalyst $\mathbf{4 1}$ bearing the smallest-sized $N$-alkyl group on the NHC emerged as the most performing catalyst in both initiation and propagation stages, even with respect to IndII-SIMes. Indeed, besides its faster initiation, complex $\mathbf{4 1}$ offers a less encumbered NHC for the approach of substrates to the metal center during the metathesis process. The performance of complex 41 also was compared with that of the benzylidene ana-

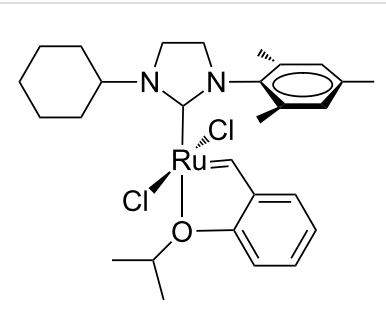

36

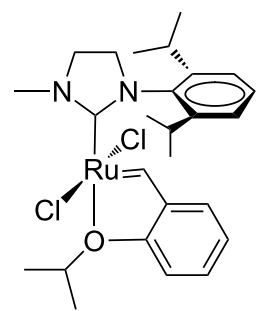

38

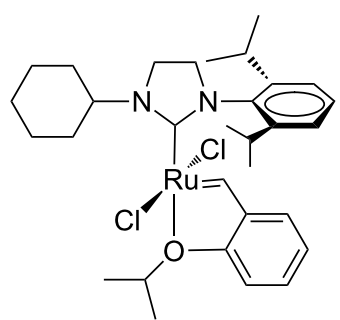

39

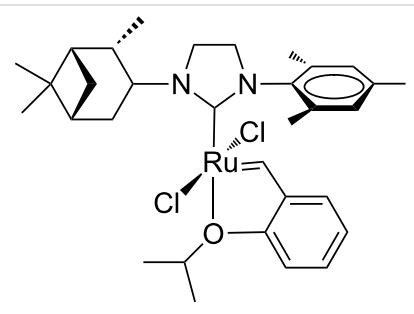

37

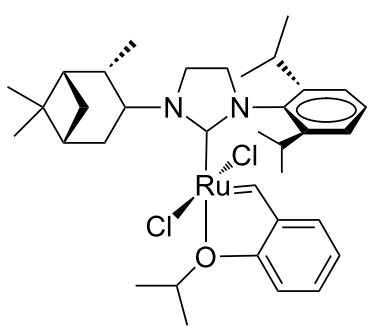

40

Figure 10: Hoveyda-type complexes with an $N$-alkyl, $N^{\prime}$-mesityl $(36,37)$ and an $N$-alkyl, $N^{\prime}$-2,6-diisopropylphenyl $(\mathbf{3 8 - 4 0 )} \mathrm{NHC}$ ligand. 
logue GII-SIMes in the RCM of 7 (Scheme 1) using various catalyst loadings $(0.125-0.5 \mathrm{~mol} \%)$. Although the benzylidene complex GII-SIMes exhibited a faster initiation than the indenylidene complex $\mathbf{4 1}$ with all the used catalyst loadings, the latter outperformed GII-SIMes in the overall catalyst efficiency, especially at the lowest catalyst loading of $0.125 \mathrm{~mol} \%$.

In 2008, Blechert and Buchmeiser et al. introduced a ruthenium complex featuring an unsymmetrical, chiral NHC ligand $\mathbf{4 4}$ and its pyridine derivative $\mathbf{4 5}$ (Figure 12) [26].

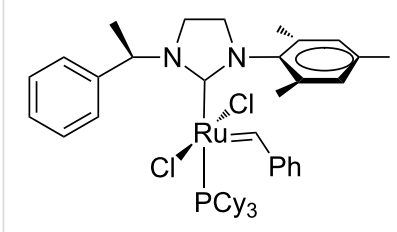

44

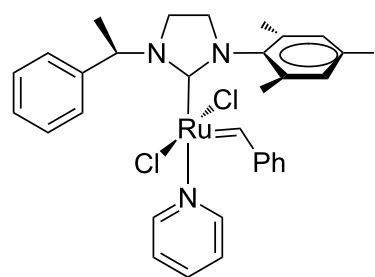

45
Figure 12: Grubbs-type complex 44 and its monopyridine derivative 45 containing a chiral $\mathrm{UNHC}$.

Both complexes revealed as efficient systems to promote the alternating copolymerization of norbornene (NBE, 46) with cyclooctene (COE, 47) and cyclopentene (CPE, 48), respectively (Scheme 6).

An NBE/COE ratio of 1:50 was found necessary to realize a copolymer containing $97 \%$ of alternating diads ([poly(NBE-alt$\left.\mathrm{COE})_{n}\right]$ ), while an NBE/CPE ratio of only 1:7 resulted in the formation of a copolymer with roughly $90 \%$ of alternating diads ([poly(NBE-alt-CPE $\left.)_{n}\right]$ ), representing the highest value found until then. The selectivity in the copolymerization was mainly ascribed to the steric interaction between the 2-phenylethyl substituent at the nitrogen and the growing polymer chain. This study was then extended to a series of unsymmetrical pyridinecontaining Ru benzylidenes (Figure 13) with $N$-alkyl $(49,50)$,
$N$-phenyl (51) and $N$-benzyl (52) substituents in comparison to their parent phosphine-containing catalysts $24 a, 25 a, 1 a$ and 53 [27].

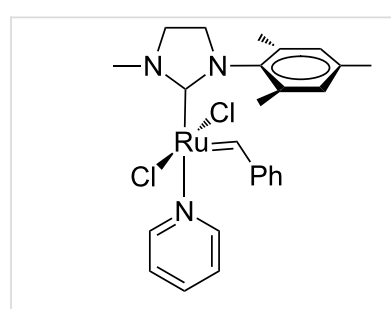

49

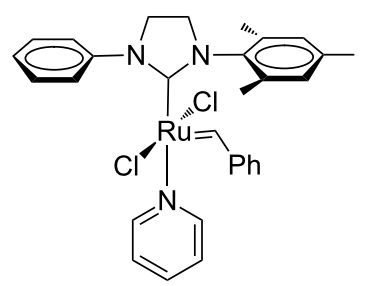

51

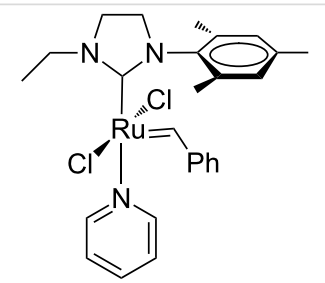

50

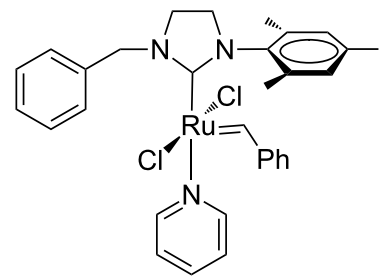

52<smiles>Cc1cc(C)c(N2CCN(Cc3ccccc3)C2[R](Cl)(Cl)C=P)c(C)c1</smiles>

53

Figure 13: Pyridine-containing complexes 49-52 and Grubbs-type complex 53.

Complexes 49 and $\mathbf{5 2}$ were obtained as monopyridine adducts, while complexes $\mathbf{5 0}$ and $\mathbf{5 1}$ were obtained as a mixture of mono- and bis(pyridine) adducts. In terms of initiation efficiency, the pyridine-derivatives turned out to be more efficient than the corresponding phosphine-containing complexes. In the copolymerization of NBE (46) and COE (47), complexes 49-52 afforded the corresponding copolymers with $95-97 \%$ of alternating diads and high cis content. In the copolymerization of NBE (46) and CPE (48), copolymers with 79-91\% of alter-

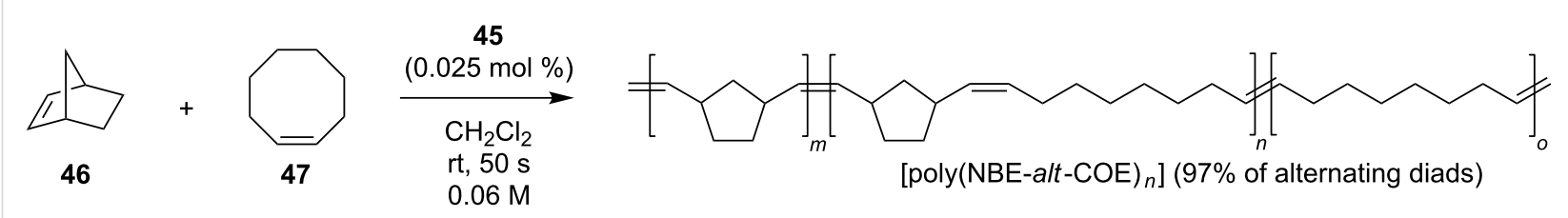

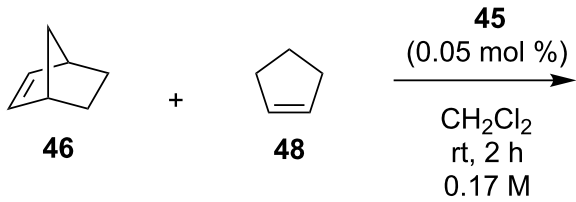

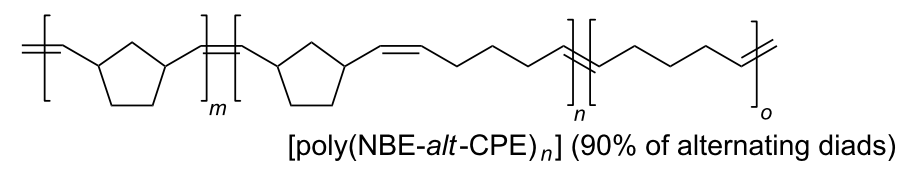


nating diads were obtained. More recently, Plenio and co-workers described a new class of Hoveyda-Grubbs-type catalysts with an $N$-alkyl, $N$ '-pentiptycenyl NHC ligand (54-57, Figure 14). The complex 58 having an $N$-mesityl, $N$ '-pentiptycenyl NHC was also reported [28].

These complexes disclosed an excellent degree of alternation in the copolymerization of NBE and COE $(0.05 \mathrm{~mol} \%$ of catalyst, $[\mathrm{NBE}]=0.14 \mathrm{M})$. Especially catalyst 56 having a cyclohexyl $\mathrm{N}$-substituent provided the copolymer with the highest amount of alternating diads (98\%) at an NBE/COE ratio of 1:10. However, the molecular mass of the copolymers was far lower than the theoretical value, suggesting that competitive chain-termination reactions occur. The pronounced steric bulk on the pentiptycenyl side of the NHC ligand compared to the other less hindered side determines two differently accessible active sites around the metal and different rates of monomer incorporation, thus dominating the selectivity in the formation of alternating copolymers. The nature of the alkyl group also plays a role in the formation of alternating diads. Indeed, the proportion of alternating copolymer increases moving from the small methyl group (54) to the large cyclohexyl group (56).

Unsymmetrical catalysts based on NHC units possessing one alkyl substituent (propyl (59) or benzyl (60)) and one mesityl substituent (Figure 15) at the nitrogen atoms were investigated by Copéret and Thieuleux et al. in the tandem ring- opening-ring-closing alkene metathesis (RO-RCM) of ciscyclooctene (47) and their performance were compared to those of the classical GII-SIMes and GII-IMes [29].

The dissymmetry of the NHC ligand in $\mathbf{5 9}$ and $\mathbf{6 0}$ allowed for the selective formation of cyclic dimeric and trimeric products in place of polymers from cyclooctene, while the symmetrical analogues GII-SIMes and GII-IMes led mainly to polymers (Figure 15).

Following a study on degenerate metathesis reactions that had highlighted a strong catalytic preference of unsymmetrical $N$-alkyl, $N$ '-aryl complexes to propagate as a methylidene species [30], Grubbs and co-workers developed a variety of unsymmetrical metathesis Hoveyda-type complexes (61-69, Figure 16) for applications in the ethenolysis of methyl oleate (70, Scheme 7) [31].

The ethenolysis reaction, in fact, requires catalyst stability as a propagating methylidene species to achieve high product selectivity and turnover numbers (TONs). The catalysts 61-69, tested together to the phosphine-containing catalyst 32, were found to be highly selective toward the formation of the desired ethenolysis products $\mathbf{7 1}$ and $\mathbf{7 2}$ (Scheme 7), and provided good yields and TONs at $50{ }^{\circ} \mathrm{C}$ and low catalyst loading (100 ppm, Table 2). Furthermore, many of the screened catalysts showed good stability toward propagation as a methylidene species. The
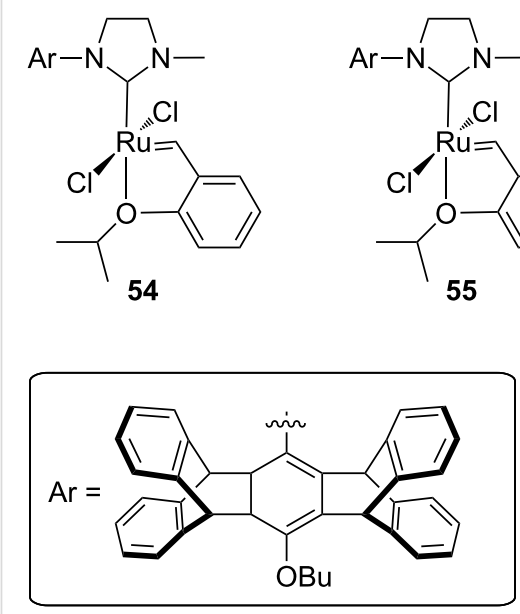<smiles>CC(C)Oc1ccccc1CN1CCN([Al])C1[R](Cl)(Cl)Cl</smiles><smiles></smiles><smiles>Cc1ccc(C)c(N2CCN([Al])C2[R](Cl)(Cl)c2ccccc2OC(C)C)c1OC(C)C</smiles>

\section{Alternating ROMP}

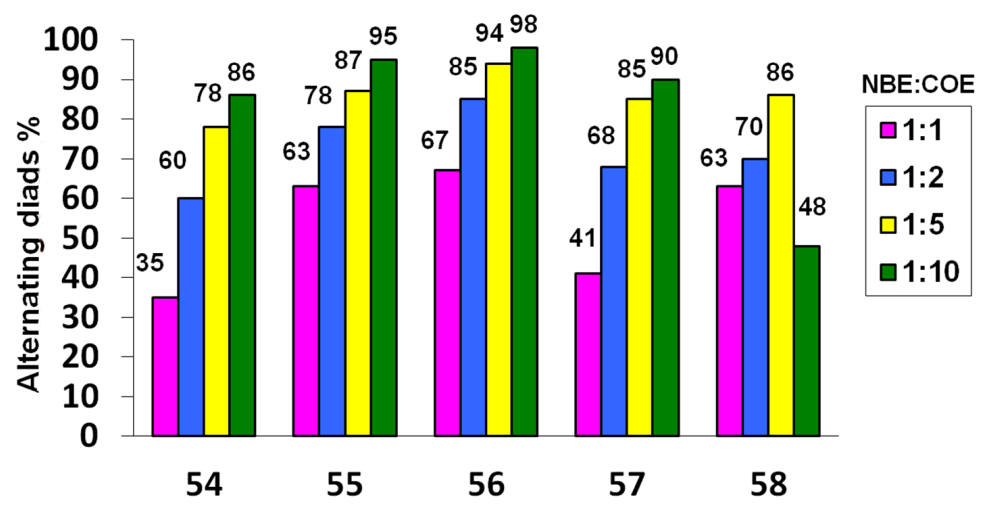




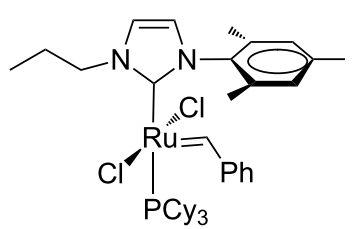

59

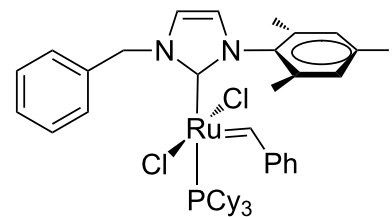

60

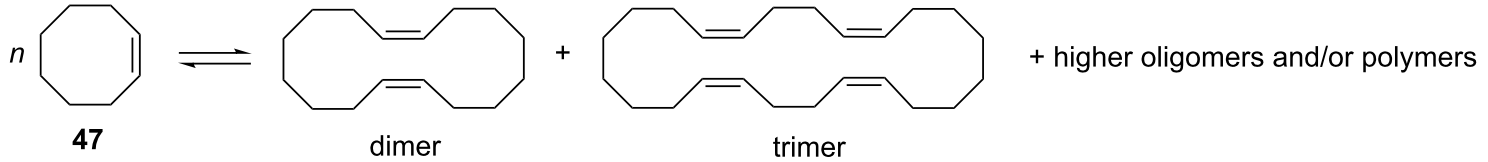

reaction conditions:

$0.01 \mathrm{~mol} \%[\mathrm{Ru}],[47]=\sim 20 \mathrm{mM}$ in toluene, $47 / \mathrm{Ru}=10000,25^{\circ} \mathrm{C}, 50-60 \mathrm{~h}$

Figure 15: Catalysts 59 and 60 in the tandem RO-RCM of 47.

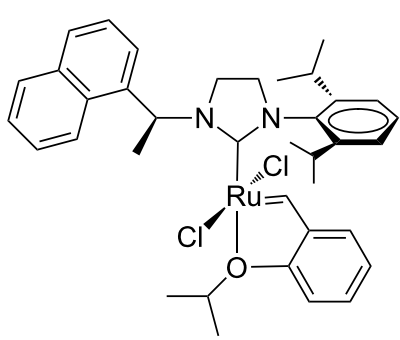

61

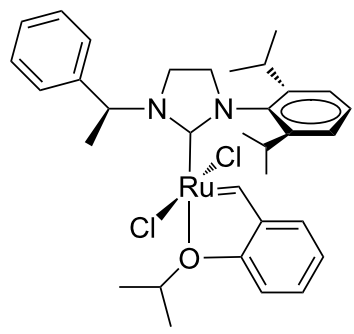

64

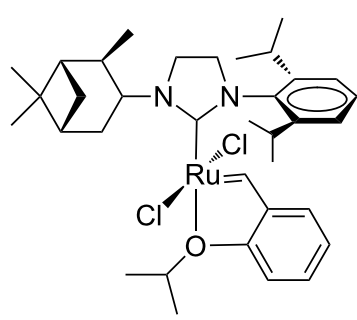

67

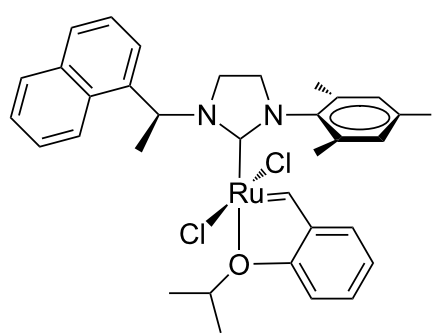

62

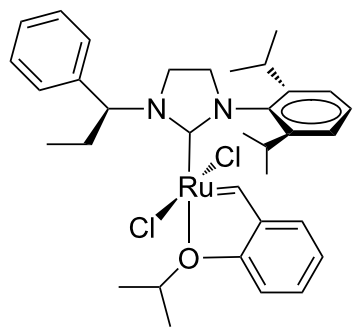

65

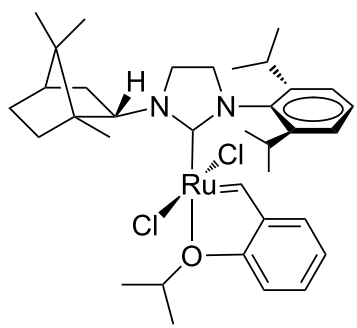

68

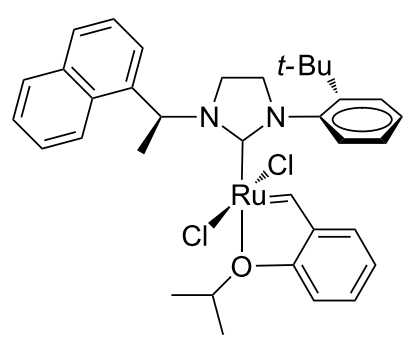

63

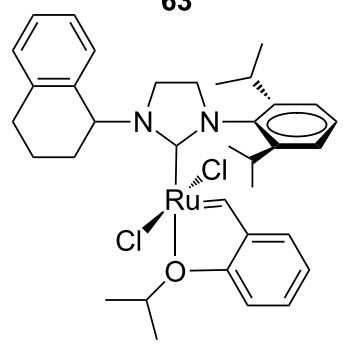

66

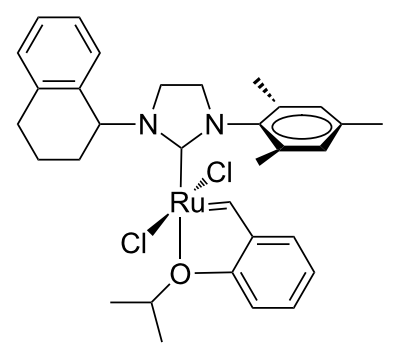

69

Figure 16: Hoveyda-type complexes 61-69 with $N$-alkyl, $N$ '-aryl NHCs.

observed selectivity seems to be controlled by the NHC sterics, as increasing steric bulkiness of the NHC ligand leads to greater selectivity and improves stability.
Catalyst 68 gave the highest selectivity (95\%) toward terminal olefins observed until then for NHC-Ru complexes (Table 2, entry 7), but with $46 \%$ yield at $500 \mathrm{ppm}$ of catalyst loading. The 
<smiles>[3H]C(C)(C)CC=CCC(C)(C)C(=O)OC</smiles>

70

\begin{tabular}{c}
$\begin{array}{c}{[\mathrm{Ru}](100 \mathrm{ppm})} \\
\mathrm{H}_{2} \mathrm{C}=\mathrm{CH}_{2}\end{array}$ \\
\hline $\begin{array}{c}150 \mathrm{psi} \\
40{ }^{\circ} \mathrm{C}, 6 \mathrm{~h}\end{array}$
\end{tabular}

$40^{\circ} \mathrm{C}, 6 \mathrm{~h}$<smiles>C=CCC(=O)OC</smiles><smiles>CC/C=C\CC(C)(C)C</smiles>

73<smiles>COC(=O)CC=CCCCCCC(=O)OC</smiles>

74

Scheme 7: Ethenolysis of methyl oleate (70).

Table 2: Ethenolysis of methyl oleate (70) with catalysts 61-69.

\begin{tabular}{ccccc} 
entry & complex & conversion (\%) & selectivity (\%) & TON \\
\hline 1 & 61 & 54 & 86 & 46 \\
2 & 62 & 11 & 77 & 9 \\
3 & 64 & 52 & 86 & 45 \\
4 & 65 & 42 & 86 & 36 \\
5 & 66 & 59 & 87 & 51 \\
6 & 67 & 52 & 89 & 360 \\
7 & 68 & 15 & 95 & 5070 \\
8 & 69 & 17 & 69 & 460 \\
\end{tabular}

chiral catalysts 61, 64, 65, 67 and 68 (Figure 16) were also investigated in the model asymmetric ring-opening cross metathesis (AROCM) of cis-5-norbornene-endo-2,3-dicarboxylic anhydride (75) with styrene (Scheme 8, Table 3) [32].

In this reaction complex $\mathbf{6 8}$ showed the highest selectivity for the formation of the desired product $\mathbf{7 6}(82 \%$ ee, Table 3 , entry 5), comparable to the best ruthenium catalysts investigated in this AROCM reaction. All complexes gave side products 77 and/or $\mathbf{7 8}$ resulting from metathesis reactions of propagating ruthenium methylidene species.
In the same year, Grubbs and co-workers reported on the synthesis of highly thermally stable complexes containing a sterically encumbered $N$-tert-butyl substituent (79-82, Figure 17) which enables their application for latent olefin metathesis [33].

The complexes $\mathbf{7 9}$ and $\mathbf{8 1}$ having chloride ligands exhibited excellent latent behavior toward self-CM of 1-hexene, giving no conversion at room temperature and dimerization at $85{ }^{\circ} \mathrm{C}$. Exchanging the chloride ligands for iodide ligands led to catalysts 80 and $\mathbf{8 2}$ with superior latent behavior that allowed

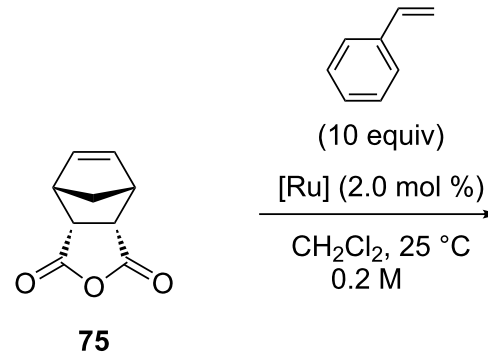<smiles>O=C1OC(=O)[C@@H]2[C@@H]1[C@@H](/C=C/c1ccccc1)C[C@@H]2/C=C/c1ccccc1</smiles>

77<smiles>C=C[C@H]1C[C@H](/C=C/c2ccccc2)[C@H]2C(=O)OC(=O)[C@H]12</smiles>

76

Scheme 8: AROCM of cis-5-norbornene-endo-2,3-dicarboxylic anhydride (75) with styrene. 
Table 3: AROCM of cis-5-norbornene-endo-2,3-dicarboxylic anhydride (75) with catalysts 61, 64, 65, 67 and 68.

\begin{tabular}{|c|c|c|c|c|c|}
\hline entry & complex & time $(h)$ & conversion (\%) & yield $(\%)$ & ee $76(\%)$ \\
\hline 1 & 61 & 5.5 & 60 & 60 & 69 \\
\hline 2 & 64 & 0.5 & 99 & 69 & 14 \\
\hline 3 & 65 & 0.5 & 99 & 73 & 9 \\
\hline 4 & 67 & 5.5 & 98 & 65 & 33 \\
\hline 5 & 68 & 10.5 & 98 & 54 & 82 \\
\hline
\end{tabular}
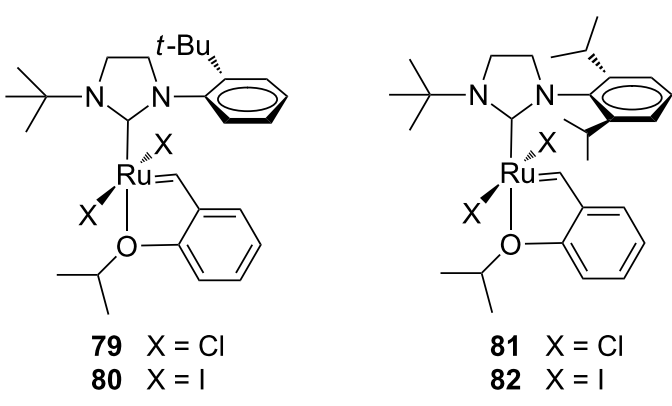

Figure 17: Hoveyda-type catalysts 79-82 with N-tert-butyl, $N^{\prime}$-aryl NHCs.

for the latent ROMP of norbornene derivatives (e.g., 83 , Scheme 9).

In order to improve the selectivities in olefin metathesis, a small library of indenylidene and Hoveyda-type complexes bearing unsaturated unsymmetrical NHCs combining a flexible cycloalkyl moiety and a mesityl unit as N-substituents (85-89, Figure 18) was synthesized by Mauduit and co-workers [34]. These systems were tested in the RCM of sterically demanding diethyl allylmethallylmalonate (9) under standard conditions (Scheme 2) and compared to their unsymmetrical saturated NHC-Ru complexes 90-92 (Figure 18) as well as a set of commercially available catalysts having symmetrical IMes or SIMes NHC ligands.

The unsaturated indenylidene catalysts $\mathbf{8 5}$ and $\mathbf{8 6}$ were found to be more active than their saturated homologues, giving full conversions within $6 \mathrm{~h}$ and $24 \mathrm{~h}$, respectively, thus showing better performances than IndII-IMes and Hoveyda-type catalysts 87-89, 92. As for the latter ones, the introduction of unsaturated NHCs with an $\mathrm{N}$-cycloalkyl moiety did not provide any beneficial effect, since they were less efficient also than their symmetrical IMes and SIMes counterparts. The catalytic potential of the most active complex $\mathbf{8 5}$ with a cyclopentyl fragment on the NHC was explored in several RCM and $\mathrm{CM}$ reactions. Interestingly, in the RCM of $N, N$-dimethallyl- $N$-tosylamide (93) only $2 \mathrm{~mol} \%$ of $\mathbf{8 5}$ were required to produce $54 \%$ of the tetrasubstituted tosylamide 94 within $3 \mathrm{~h}$ (Scheme 10).

Moreover, catalyst 85 was quite efficient under neat conditions for the self metathesis of allylbenzene (13), showing no trace of isomerized byproducts (Scheme 11).

More recently, Olivier-Bourbigou and Mauduit demonstrated the ability of unsymmetrical $N$-cycloalkyl $\mathrm{Ru}$-indenylidene catalysts for the selective self metathesis of linear $\alpha$-olefins to longer internal linear olefins in the absence of additives to prevent isomerization [35]. Catalyst 91 with a saturated NHC ligand containing a $\mathrm{N}$-substituted cyclododecyl side chain was first evaluated at $50 \mathrm{ppm}$ loading in the self metathesis of 1-octene (96), at $50{ }^{\circ} \mathrm{C}$ under neat conditions, in comparison to symmetrical benchmark second-generation ruthenium catalysts IndII-SIMes, IndII-IMes, GII-SIMes and HGII-SIMes (Table 4). Complex 91 was found to give $70 \%$ conversion of 1 -octene (96) to the desired 7-tetradecene (97) with high selectivity (98\% after $1 \mathrm{~h}$, Table 4 , entry 1$)$. Moreover, the selectivity did not change over time (Table 4 , entry 2 ). A lower<smiles>O=C1C2C3C=CC(C3)C2C(=O)N1Cc1ccccc1</smiles>

83

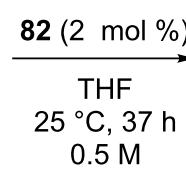
rention<smiles>C#C[C@H]1C[C@@H](C(C)C)[C@H]2C(=O)N(Cc3ccccc3)C(=O)[C@H]12</smiles>

84 


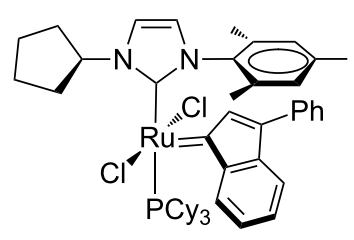

85
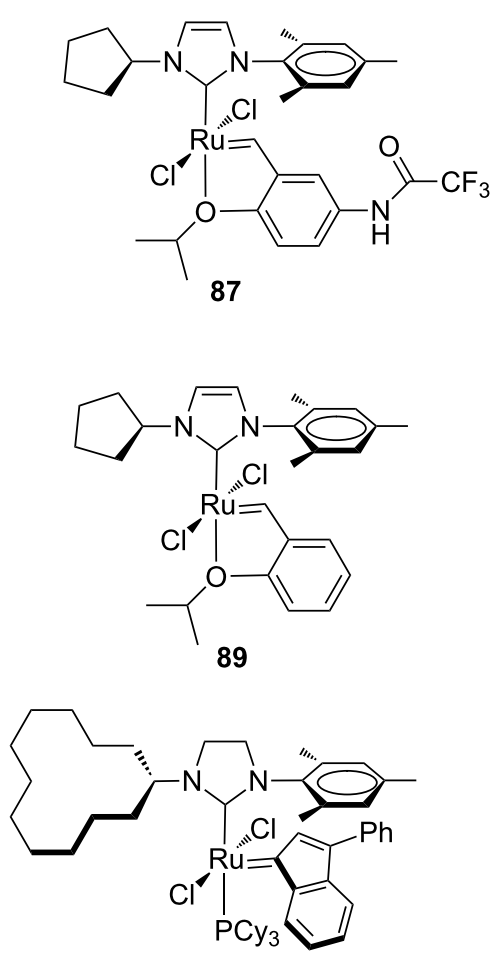

91

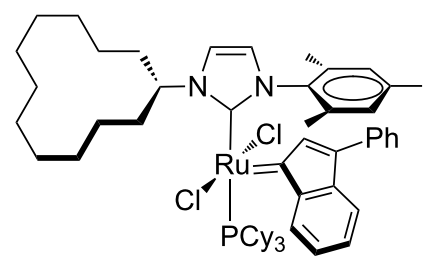

86

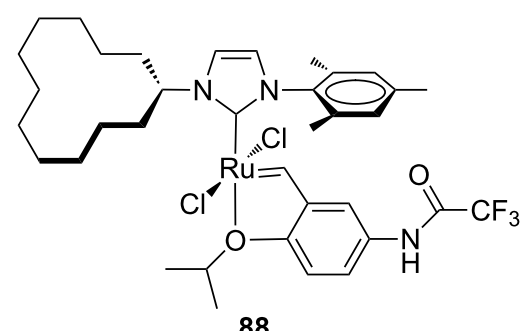

88

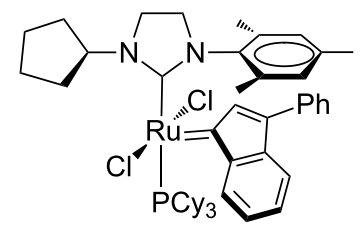

90

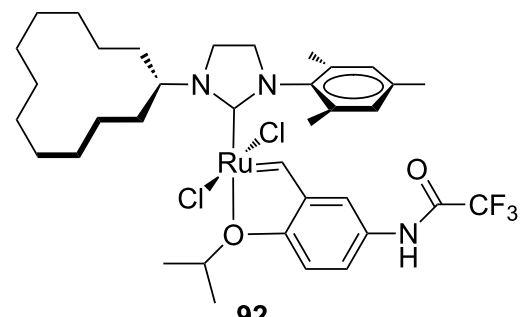

92

Figure 18: Indenylidene and Hoveyda-type complexes 85-92 with N-cycloalkyl, N'-mesityl NHCs.<smiles>C=C(C)CN([AsH])CC(=C)C</smiles>

93

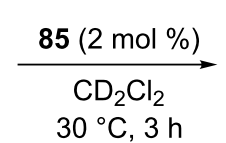

$0.1 \mathrm{M}$

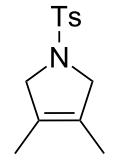

$94(54 \%$ yield $)$
Scheme 10: RCM of $N, N$-dimethallyl- $N$-tosylamide (93) with catalyst 85.

selectivity was observed with IndII-SIMes (Table 4, entries 3 and 4 ) and GII-SIMes (Table 4, entry 5), while IndII-IMes was inactive (Table 4, entry 6) and HGIIMes gave only low conversion (Table 4 , entry 7 ).

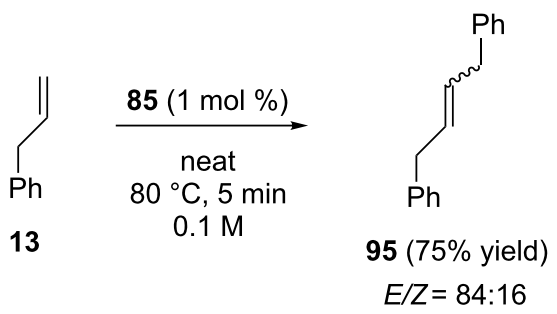

Scheme 11: Self metathesis of 13 with catalyst 85.

To render this process really attractive for industrial application, the authors also evaluated the lower-cost catalysts 85 and 86 in the self metathesis of 96 (Table 4, entries 8 and 9, respectively). Indeed, the one-step multicomponent synthesis of unsaturated 
Table 4: Self metathesis of 1-octene (96).

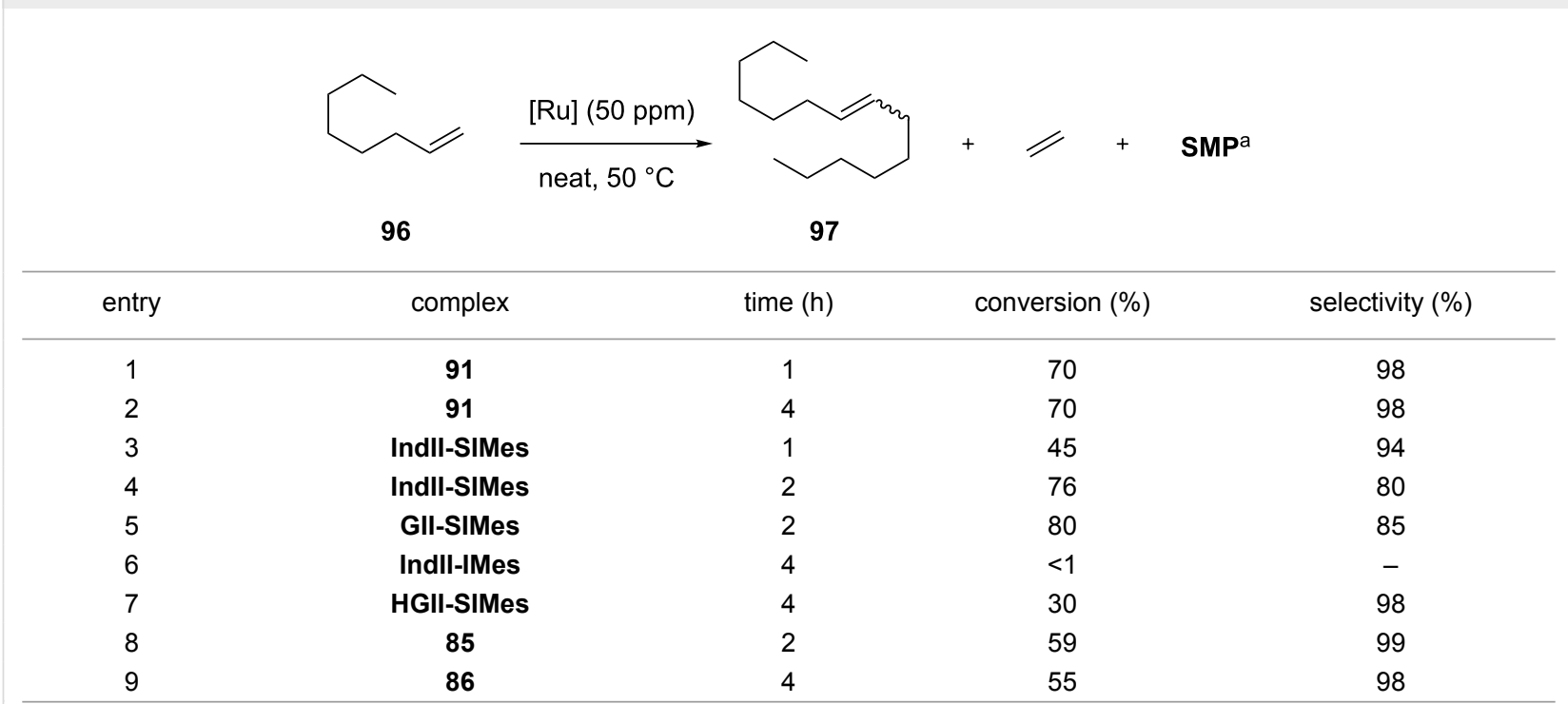

asMP: secondary metathesis products (mixture of $\mathrm{C}_{3}-\mathrm{C}_{13}$ olefins) [35].

unsymmetrical NHCs could provide a cost-effective alternative to the multistep synthesis of their saturated counterparts [36]. The catalyst $\mathbf{8 5}$ was identified as the catalyst of choice for the selective metathesis of linear $\alpha$-olefins and was successfully applied to selectively re-equilibrate the naphtha fraction $\left(\mathrm{C}_{5}-\mathrm{C}_{8}\right)$ of a Fischer-Tropsch feed derived from biomass to higher value added olefins $\left(\mathrm{C}_{9}-\mathrm{C}_{14}\right)$ that can serve as plasticizer and detergent precursors. An excellent olefin distribution with no isomerization was observed without the use of any additive even after $24 \mathrm{~h}$ of reaction performed at $50{ }^{\circ} \mathrm{C}$ under neat conditions.

\section{$\mathrm{N}$-Alkyl substituents possessing functionalities or heteroatoms}

In 2001, the Fürstner group reported on phosphine-containing ruthenium complexes having unsymmetrical NHCs characterized by an alkenyl chain replacing one of the $N$-mesityl groups of the NHC ligand (98-100, Figure 19) [37]. The complexes 98-100 were able to metathesize their own ancillary ligands, thus leading to species in which the NHC ligand is bound to the $\mathrm{Ru}=\mathrm{CHR}$ moiety to form a metallacycle (101 and 102, Figure 19). The basic idea was that these catalysts might be able to regenerate themselves upon consumption of the monomer in the reaction media. Variants of these complexes with a silyl ether or a perfluoroalkyl chain on one of the nitrogens of the NHC were also presented (103 and 104, Figure 19).

The catalytic behavior of complexes $\mathbf{9 8}-\mathbf{1 0 0}$ and 101, 102 was tested in the RCM of $N, N$-dimethallyl- $N$-tosylamide (93) to form the corresponding tetrasubstituted cycloolefin 94
(Scheme 10; reaction performed in toluene at $80{ }^{\circ} \mathrm{C}$ with $5 \mathrm{~mol} \%$ of catalyst). All the complexes were able to achieve the cyclization, although the catalytic activity of the homologous series 98-100 was found to be strongly dependent on the tether length between the alkene group and the metal center. This effect is likely related to their different ability in forming the corresponding chelate complexes in situ (Figure 19).

Importantly, later on Grubbs and co-workers utilized this kind of catalysts, featuring a chelating N-to-Ru arm, for the preparation of cyclic polymers from cyclic monomers via a ring-expansion metathesis polymerization (REMP) process [38,39]. With the aim of developing catalysts suitable for covalent immobilization on various supports, Fürstner et al. reported on the preparation of some unsymmetrical complexes containing pendant protected (105-108) and unprotected (109-111) hydroxyalkyl chains on their NHCs (Figure 20) [40].

Complex 109 was easily immobilized on functionalized silica gel and the resulting complex 112 (Figure 20) was tested in prototype RCM reactions. In comparison to its homogeneously soluble analogues 109 and 110, complex 112 required longer reaction times to give the same yields, but was reusable up to three times.

Interestingly, during investigations carried out to anchor this type of ruthenium complexes by physisorption rather than chemisorption, an unexpected molecular rearrangement of their ligand sphere, determining a cis orientation of the neutral ligands, was observed (113 and 114, Figure 20). The same 


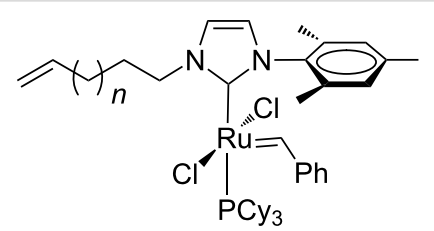

$$
\begin{array}{ll}
98 & n=1 \\
99 & n=2 \\
100 & n=4
\end{array}
$$

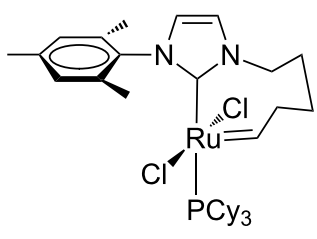

101

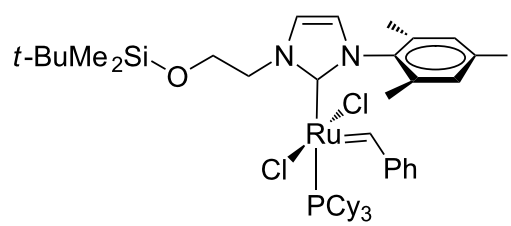

103

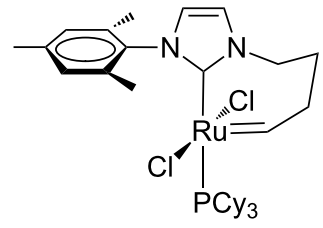

102

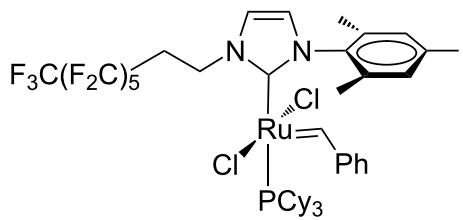

104

Figure 19: Grubbs-type complexes 98-104 with N-alkyl, N'-mesityl NHCs.

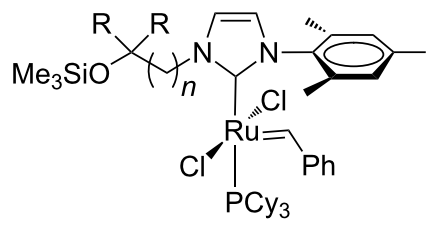

$105 n=5, \mathrm{R}=\mathrm{H}$

$106 n=2, \mathrm{R}=\mathrm{H}$

$107 n=2, \mathrm{R}=\mathrm{Me}$

$108 n=1, \mathrm{R}=\mathrm{H}$

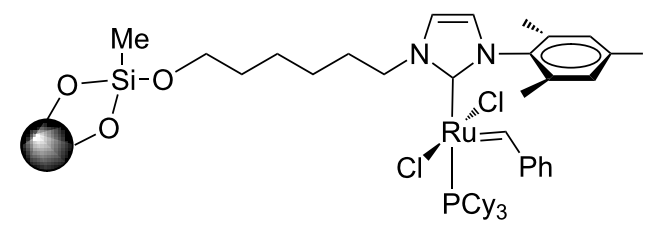

112

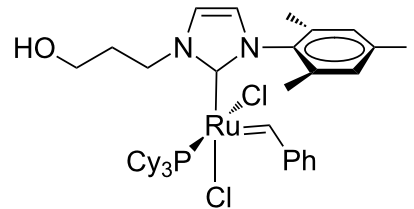

114

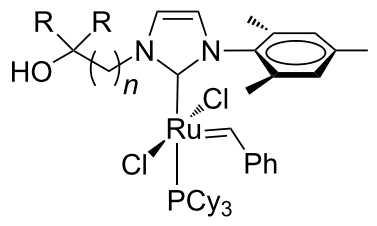

$109 n=5, \mathrm{R}=\mathrm{H}$

$110 n=2, \mathrm{R}=\mathrm{H}$

$111 n=2, \mathrm{R}=\mathrm{Me}$

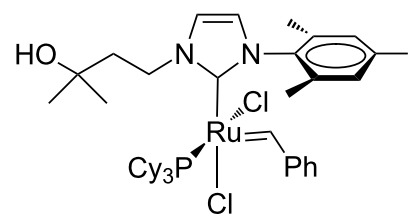

113

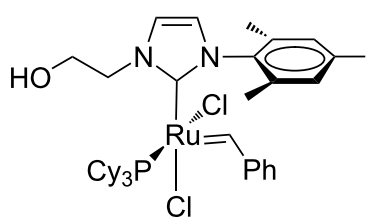

115

Figure 20: Grubbs-type complexes 105-115 with N-alkyl, N'-mesityl ligands. 
unusual cis configuration was displayed by complex 115 (Figure 20) upon release from its precursor $\mathbf{1 0 8}$ by deprotection under acidic conditions.

The cis isomers $\mathbf{1 1 3}-\mathbf{1 1 5}$ exhibited catalytic activity only at high temperatures, where they likely reassume the trans form which is characteristic for the Grubbs-type ruthenium carbene complexes.

In order to develop a new structural class of highly performing NHC-based metathesis catalysts with $\mathrm{N}$-alkyl groups, ruthenium benzylidene complexes containing carbohydrate-based NHCs derived from glucose (116) and galactose (117, Figure 21) were reported in 2009 [41].

These complexes were characterized in solution by NMR techniques which revealed, at room temperature, the presence of rotameric species resulting from rotation about the $\mathrm{Ru}-\mathrm{C}$ (benzylidene) bond. The catalytic behavior of $\mathbf{1 1 6}$ and 117 was examined in standard RCM, CM, ROMP olefin metathesis reactions. Interestingly, $\mathbf{1 1 6}$ and $\mathbf{1 1 7}$ differing only at one stereocenter showed different kinetic behavior in the RCM of diethyl diallylmalonate (7, Scheme 1 ; reaction temperature $40{ }^{\circ} \mathrm{C}$ ), where $\mathbf{1 1 7}$ displayed a higher activity than catalyst $\mathbf{1 1 6}$. Furthermore, they showed surprising selectivity ( $E / Z$ ratio around 3 ) in the CM of allylbenzene (13) and cis-1,4-diacetoxy2-butene (Scheme 4; reaction temperature $40{ }^{\circ} \mathrm{C}$ ) compared to the benchmark catalysts GII-IMes and GII-SIMes, indicating that the steric bulk of the carbohydrate plays a role in influencing the geometry of the resulting olefinic product. Given the chiral nature of the carbohydrate attached to the NHC, complexes 116 and 117 were tested in the AROCM of a variety of norbornene derivatives with styrene. While isolated yields were generally excellent, enantiomeric excesses were poor.

The effect of a dangling amine tether incorporated into the NHC ligand on the catalytic efficiency of ruthenium benzylidene complexes was examined by Fryzuk et al. (118, Figure 22) [42].

NMR studies showed that complex 118 exists as a mixture of two rotational isomers in a 7:1 ratio. The major isomer was characterized by X-ray crystallography, while the minor isomer

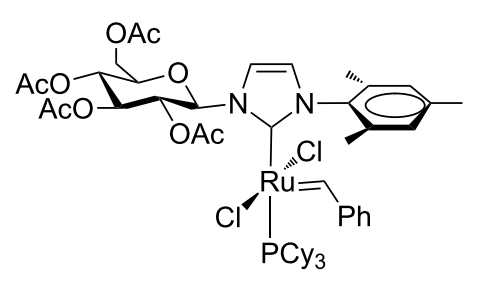

116

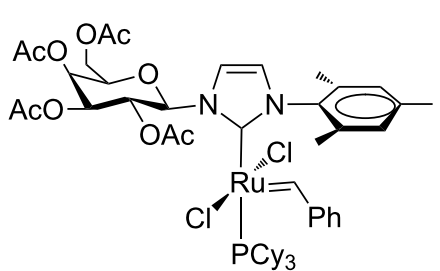

117

Figure 21: Complexes 116 and 117 bearing a carbohydrate-based NHC.

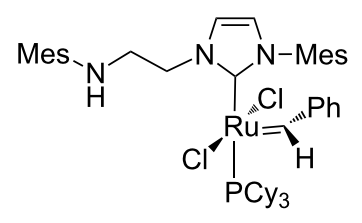

118

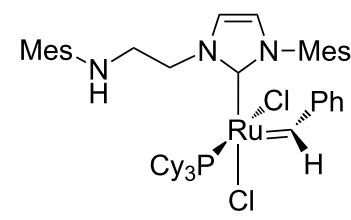

syn -118<smiles></smiles>

anti-118<smiles>CN1CCN2C=CN(C)C2([Ge](Cl)(Cl)c2ccccc2)C1(Cl)n1cccc1</smiles>

119

Figure 22: Complexes 118 and 119 bearing a hemilabile amino-tethered NHC. 
was characterized only in solution and was identified as consistent with two possible structures (syn- and anti-118). In syn-118 the two chloro ligands are cis disposed and the $\mathrm{PCy}_{3}$ unit is cis to both the NHC and the benzylidene, whereas in anti-118 the $\mathrm{PCy}_{3}$ unit and the benzylidene are trans with respect to the $\mathrm{Ru}=\mathrm{CHPh}$ double bond. Moreover, no coordination of the tethered amine to the ruthenium center was detected in the species 118 by NMR spectroscopy. Evidence for coordination of the amino arm in solution and in the solid state was observed in its derived monopyridine adduct 119 (Figure 22). Complex 118 was found less active than GII-SIMes and GII-IMes in model RCM of 7 and ROMP of $\mathbf{1 6}$ (see Scheme 1 and Scheme 5, respectively). In the RCM of 7, catalyst 118 gave $25 \%$ conversion in 30 min, while GII-SIMes and GII-IMes reached $96 \%$ and $74 \%$ conversion, respectively, within the same time. As for the ROMP of 16 , only $40 \%$ conversion was observed after $4 \mathrm{~h}$ with 118, while full conversion was registered for GII-SIMes and GII-IMes in 6 and $80 \mathrm{~min}$, respectively. The catalyst effi- ciency is further reduced in the pyridine derivative $\mathbf{1 1 9}$, suggesting that the pendant amine is deleterious for catalyst performance.

\section{Ruthenium catalysts coordinated with $\mathrm{N}$-benzyl, $N^{\prime}$-aryl NHCs}

The effect of replacing one of the mesityl groups of the NHC ligand with a flexible benzyl group on the catalytic properties of the resulting ruthenium complexes was studied by Grela and co-workers, who synthesized indenylidene complexes 120-126 $[43,44]$ (Figure 23). Substituents in the benzyl group were introduced to modify the steric and electronic properties of the ligand and/or to allow additional coordination to the metal center.

The catalytic behavior of 120-126 was investigated in standard metathesis reactions using commercial grade solvents in air and compared to that of commercially available IndII-SIMes. Cata-<smiles></smiles>

120

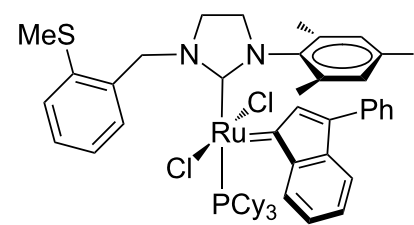

122

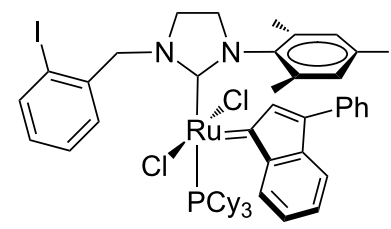

124<smiles></smiles>

121

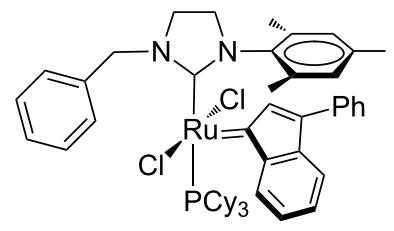

123

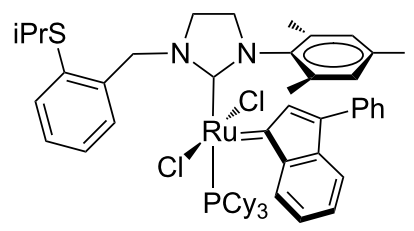

125

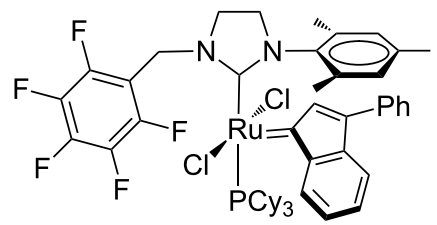

126 
lysts 120, 121, 123, 124 and 126 showed a better performance than IndII-SIMes in the RCM of 7 (Scheme 1), whereas the sulfur-containing catalysts $\mathbf{1 2 2}$ and $\mathbf{1 2 5}$ displayed lower activity. In more detail, 120, 121, 123 and 124 exhibited similar behavior, in spite of the different nature of aryl substituents, while 126 was found to be less efficient. Solvent tests on IndIISIMes, 123 and 126 demonstrated that dichloromethane is a better solvent with respect to toluene, even if in toluene the initiation of catalyst 126 is faster. The low activity of $\mathbf{1 2 2}, \mathbf{1 2 5}$ and 126 was rationalized by supposing the presence of an interaction between the metal and the heteroatoms of the benzyl substituents $[15,43,44]$. Complexes $\mathbf{1 2 0}, \mathbf{1 2 1}, \mathbf{1 2 3}$, and $\mathbf{1 2 4}$ significantly outperformed commercial IndII-SIMes in the RCM of diethyl allylmethallylmalonate (9) as well. On the contrary, they appeared not suitable in the synthesis of tetrasubstituted olefins. Indeed, they were tested at $60{ }^{\circ} \mathrm{C}$ in the RCM of $N, N$ dimethallyl- $N$-tosylamide $(\mathbf{9 3}$, Scheme 10 ; reaction performed in toluene at $80^{\circ} \mathrm{C}$ with $5 \mathrm{~mol} \%$ of the catalyst), giving conversions between $30-40 \%$, as observed also for the commercial catalyst IndII-SIMes.
The catalysts $\mathbf{1 2 0}$ and $\mathbf{1 2 1}$ were also tested in the ring-closing ene-yne metathesis reaction (RCEYM) of standard substrate 127. Both catalysts revealed slightly more active than IndIISIMes, with 121 being the most efficient (Table 5, entry 1). Catalyst 120 showed the highest activity in the RCM of the amide-based substrate $\mathbf{1 2 9}$ (Table 5, entry 2) and in the CM of 13 with 14, but with a slightly lower $Z$-selectivity (Table 5, entry 3$)$.

Finally, in the presence of catalysts 120,121 and 123, diastereoselectivities higher than those achieved in the presence of GIISIMes, HGII-SIMes and IndII-SIMes were observed in the diastereoselective ring-rearrangement metathesis (dRRM) of cyclopentene 131 (Scheme 12).

The presence of a nitro group at the ortho or para positions of the benzyl substituent (134 and $\mathbf{1 3 5}$ in Figure 24), reported by Malinowska and co-workers [45], led to higher activities in the RCM of 7 and 9 (Schemes 1 and 2), with respect to the commercial IndII-SIMes, but significantly lower if compared to

\begin{tabular}{|c|c|c|c|c|c|c|}
\hline entry & substrate & product & catalyst (mol \%) & $T\left({ }^{\circ} \mathrm{C}\right)$ & $t(\mathrm{~h})$ & isolated yield (\%) \\
\hline 1 & 127 & 128 & $\begin{array}{c}\text { IndII-SIMes (2) } \\
120(2) \\
121(2) \\
134(2) \\
135(2) \\
136(2) \\
137(2) \\
138(2) \\
139(2) \\
140(2) \\
141(2) \\
142(2)\end{array}$ & $\begin{array}{l}30 \\
30 \\
30 \\
40 \\
40 \\
50 \\
50 \\
50 \\
50 \\
50 \\
50 \\
50\end{array}$ & $\begin{array}{c}8 \\
6 \\
5 \\
8 \\
8 \\
2 \\
2 \\
2 \\
1.5 \\
1.5 \\
1.5 \\
1.5\end{array}$ & $\begin{array}{l}96^{a} \\
94^{a} \\
96^{a} \\
99^{b} \\
99^{b} \\
92^{c} \\
91^{c} \\
92^{c} \\
89^{c} \\
91^{c} \\
89^{c} \\
91^{c}\end{array}$ \\
\hline 2 & $\begin{array}{l}11 \\
O \\
129\end{array}$ & 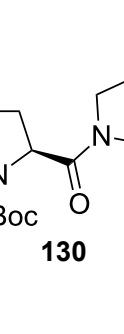 & $\begin{array}{c}\text { IndII-SIMes (1) } \\
120(1) \\
121(1) \\
136(1) \\
137(1) \\
138(1) \\
139(1) \\
140(1) \\
141(1) \\
142(1)\end{array}$ & $\begin{array}{l}50 \\
50 \\
50 \\
50 \\
50 \\
50 \\
50 \\
50 \\
50 \\
50\end{array}$ & $\begin{array}{c}2.5 \\
1 \\
2 \\
1.25 \\
2 \\
1 \\
3 \\
3 \\
3 \\
3\end{array}$ & $\begin{array}{l}94^{a} \\
96^{a} \\
91^{a} \\
87^{c} \\
89^{c} \\
92^{c} \\
85^{c} \\
94^{c} \\
88^{c} \\
90^{c}\end{array}$ \\
\hline 3 & $\begin{array}{l}14 \\
\text { OAc }\end{array}$ & 15 & $\begin{array}{c}\text { IndII-SIMes (2.5) } \\
120(2.5) \\
121(2.5) \\
134(2.5) \\
135(2.5) \\
136(2.5) \\
137(2.5) \\
138(2.5) \\
139(2.5) \\
140(2.5) \\
141(2.5) \\
142(2.5)\end{array}$ & $\begin{array}{l}30 \\
30 \\
30 \\
30 \\
30 \\
50 \\
50 \\
50 \\
50 \\
50 \\
50 \\
50\end{array}$ & $\begin{array}{c}20 \\
20 \\
20 \\
20 \\
20 \\
2 \\
2 \\
2 \\
2 \\
1.5 \\
1.5 \\
1.5\end{array}$ & $\begin{array}{c}74(E / Z=8: 1)^{\mathrm{a}} \\
80(E / Z=9: 1)^{\mathrm{a}} \\
74(E / Z=11: 1)^{\mathrm{a}} \\
45(E / Z=4: 1)^{\mathrm{b}} \\
86(E / Z=5: 1)^{\mathrm{b}} \\
89(E / Z=7.1: 1)^{\mathrm{c}} \\
76(E / Z=7.9: 1)^{\mathrm{c}} \\
93(E / Z=6: 1)^{\mathrm{c}} \\
74(E / Z=3.6: 1)^{\mathrm{c}} \\
80(E / Z=7: 1)^{\mathrm{c}} \\
81(E / Z=8: 1)^{\mathrm{c}} \\
78(E / Z=6.5: 1)^{\mathrm{c}}\end{array}$ \\
\hline
\end{tabular}

aRef [43]; ' $\operatorname{Ref}[45] ;{ }^{c} \operatorname{Ref}[46]$ 


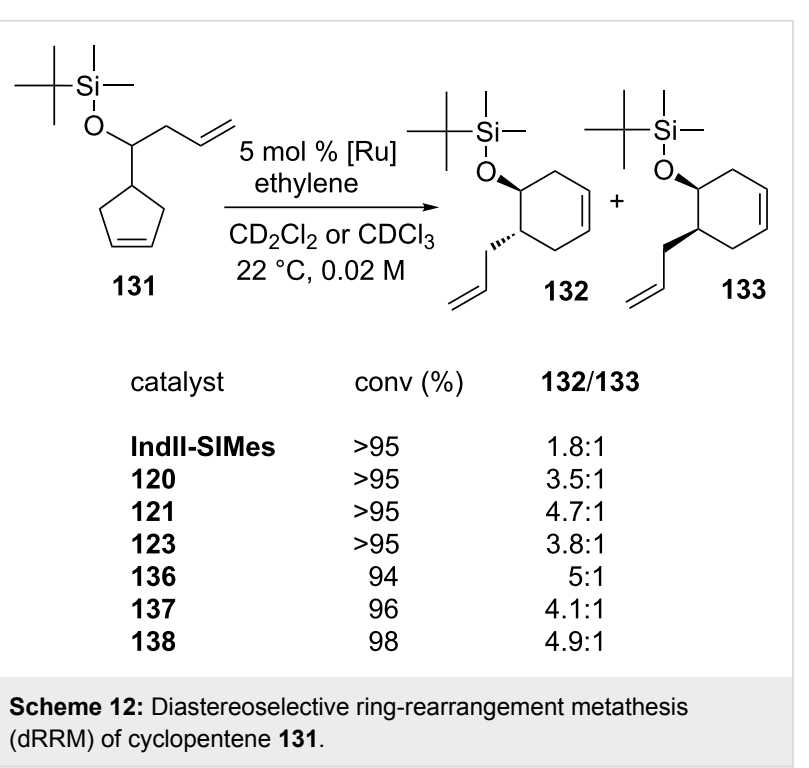

catalysts $120,121,123$ and $\mathbf{1 2 4}$. A scarce activity toward the formation of tetrasubstituted olefin 12 (Scheme 3) was also observed. Complexes $\mathbf{1 3 4}$ and $\mathbf{1 3 5}$ were tested in RCEYM of $\mathbf{1 2 7}$ (Table 5, entry 1) showing a good efficiency and in the CM of $\mathbf{1 3}$ and $\mathbf{1 4}$ (Table 5, entry 3), where interesting $Z$-selectivities can be achieved.

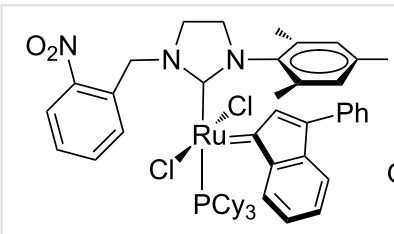

134

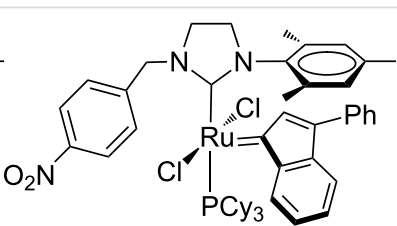

135
Figure 24: Indenylidene-type complexes 134 and 135 with $N$-nitrobenzyl, N'-mesityl NHCs.

Recently, Grela and co-workers modified the previously reported $N$-benzyl, $N$ '-aryl NHC-Ru complexes 120, 121 and 123, by synthesizing the analogous Hoveyda-type derivatives 136-138 (Figure 25). Additionally, the behavior of catalysts 136-138 was compared with that of complexes bearing an $N$-Dipp (Dipp $=2,6$-diisopropylphenyl) substituent in place of the $N$-mesityl group (139-142 in Figure 26) [46].

As expected, the $N^{\prime}$-Dipp complexes displayed a higher stability with respect to the $N^{\prime}$-mesityl complexes. Nevertheless, complexes 136-138 were more active than 139-142 in the $\mathrm{RCM}$ of 7 , conducted at $50{ }^{\circ} \mathrm{C}$ and none of those catalysts outperformed HGII-SIMes and HGII-SIPr. Analogous results were observed in the RCM of more crowded substrates. The similar behavior of $\mathbf{1 4 1}$ and $\mathbf{1 4 2}$ indicated that steric effects are more relevant than electronic effects.
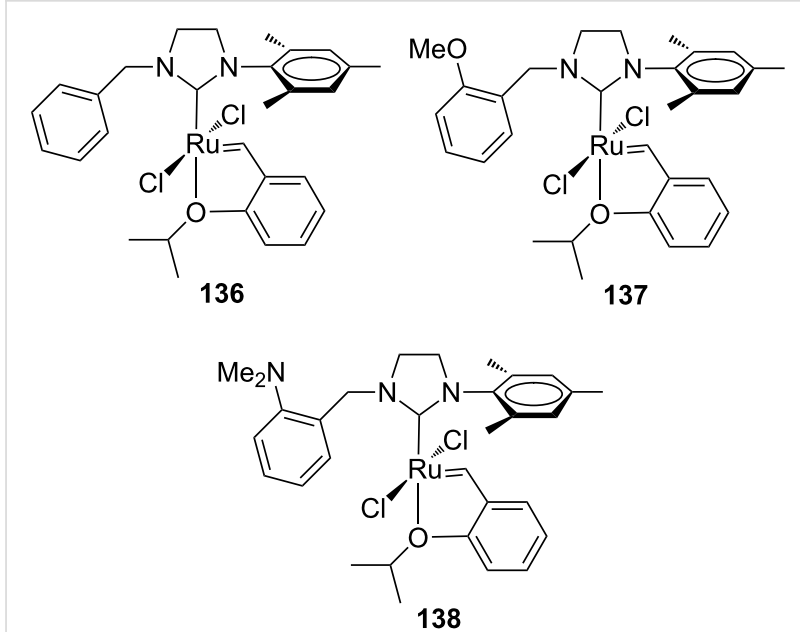

Figure 25: Hoveyda-type complexes 136-138 with $N$-benzyl, N'-mesityl NHCs.

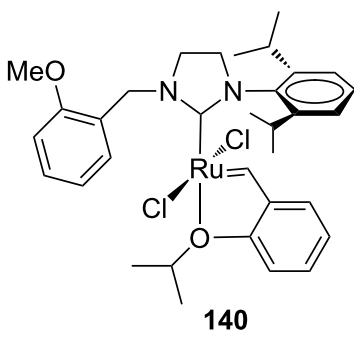

139<smiles>[Y14]c1ccccc1CN1CCN(c2ccccc2C(C)C)C1[R](Cl)(Cl)/C=C/c1ccccc1OC(C)C</smiles><smiles>CC(C)Oc1ccccc1CN1CCN(Cc2ccccc2C(F)(F)F)C1[R](Cl)(Cl)c1cccc(C(C)C)c1N(C(C)C)C(C)C</smiles>

Figure 26: Hoveyda-type complexes 139-142 with $N$-benzyl, $N$ '-Dipp NHC.

Catalysts 136-142 were tested in the RCEYM of 127, in the RCM of 129 and in the CM of 13 and 14 (Table 5, entry 3). According to the experimental results, mesityl-bearing catalysts generally gave better yields than Dipp-containing analogues. In the presence of 136-138, a high selectivity in the dRRM of cyclopentene 131 was also observed (Scheme 12). Self metathesis of 1-octene (96) was conducted in the presence of $\mathbf{1 3 6}, \mathbf{1 3 7}$, 139 and 140, in order to selectively obtain tetradec-7-ene (97). The presence of the $N$-benzyl substituent was crucial to achieve high yield (up to $80 \%$ ) of the desired product, whereas commercial HGII-SIMes and HGII-SIPr, despite the higher reaction rate, gave mainly a mixture of byproducts. 


\section{Ruthenium catalysts coordinated with $N$-heteroarylmethyl, $N$ '-aryl NHCs}

To further modify the electronic and steric properties of the NHC ligand and consequently, to improve efficiency of the resulting ruthenium catalysts, the Grela group focused on the development of new ruthenium indenylidene and Hoveyda-type complexes bearing unsymmetrical NHCs containing a heteroaromatic moiety (143-147, Figure 27) [47].

The catalytic performances of $\mathbf{1 4 3 - 1 4 7}$ were examined in model RCM and CM metathesis reactions under air in commercial grade toluene and compared to benchmark complexes IndII-SIMes and HGII-SIMes. Under these conditions all the catalysts tested showed very high activity in RCM transformations, with the newly developed systems requiring shorter reaction times to give quantitative conversion. In the RCEYM of 127, complexes 143, 146 and 147 were performing less effectively than all the other ones, however, no clear relationship between heterocyclic substituents and activity can be found. In the CM of allylbenzene (13) and cis-1,4-diacetoxy-2-butene (14), all of the new catalysts gave higher amounts of the $Z$ isomer than IndII-SIMes and HGII-SIMes. Indeed, 143-147 showed $E / Z$ ratios in the range of 3.2-4.0, while IndII-SIMes and HGII-SIMes provided $E / Z$ ratios of 9.4 and 9.3, respectively. The complexes 143-147 displayed also better diastereoselectivities in the dRRM reaction of $\mathbf{1 3 1}$ (Scheme 12) than the commercial catalysts GII-SIMes, HGII-SIMes and IndII-SIMes.
The synthesis of indenylidene and Hoveyda-type complexes bearing $N$-phenylpyrrole and $N$-phenylindole moieties on their NHCs was also attempted [48]. Most of them revealed difficult to prepare and unstable apart from the Hoveyda-type complexes 148 and 149 (Figure 28).
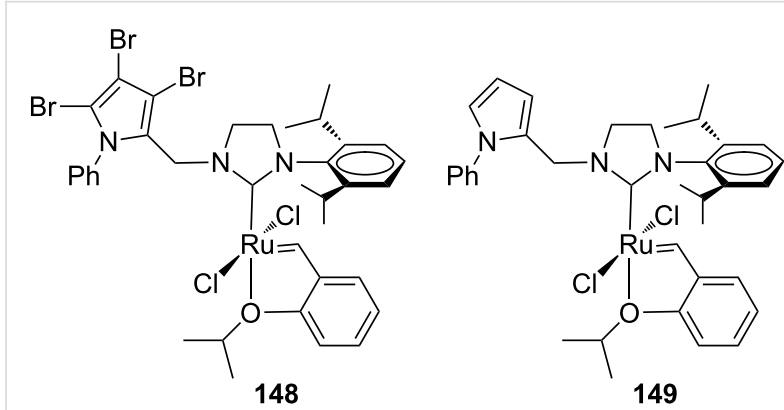

Figure 28: Hoveyda-type complexes 148 and 149 with $N$-phenylpyrrole, N'-mesityl NHCs.

These two systems were tested in standard RCM and CM reactions and complex 148 with a perbrominated $N$-phenylpyrrole moiety revealed as more stable and active than its parent catalyst 149. Both complexes were found completely inactive in $\mathrm{RCM}$ at room temperature, becoming active only at higher temperature $\left(80{ }^{\circ} \mathrm{C}\right)$. Computational studies suggested that the rarely occurring phenyl-ruthenium intramolecular interactions are responsible for lower stability and slower reaction initiation.

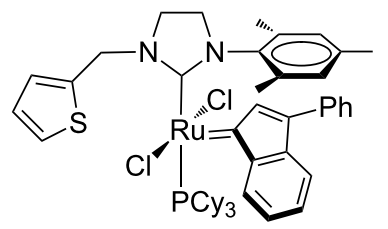

143

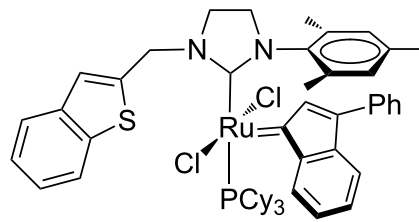

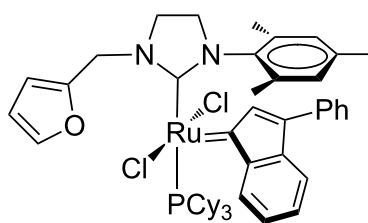

144

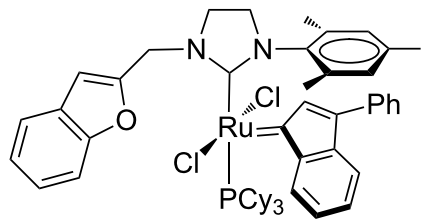

146

Figure 27: Indenylidene (143-146) and Hoveyda-type (147) complexes with N-heteroarylmethyl, N'-mesityl NHCs. 


\section{Ruthenium catalysts coordinated with $\mathrm{N}$-trifluoromethyl benzimidazolidene $\mathrm{NHCs}$}

With the goal to develop chemoselective catalysts, ruthenium complexes containing unsymmetrical $N$-trifluoromethyl NHCs were introduced by Togni et al. (150-152, Figure 29) [49].<smiles>FC(F)(F)N1c2ccccc2N(c2ccccc2)C1[R](Cl)(Cl)/C=C/c1ccccc1</smiles>

150<smiles>[R5]C(Cl)(c1ccccc1)[R](Cl)(Cl)C1N(c2cc(C(F)(F)F)cc(C(F)(F)F)c2)c2ccccc2N1C(F)(F)F</smiles>

152<smiles>CC(C)N1c2ccccc2N(c2ccc(C(F)(F)F)cc2)C1[R](Cl)(Cl)(Cl)/C=C\c1ccccc1</smiles>

154

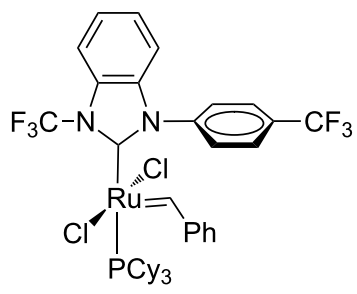

151

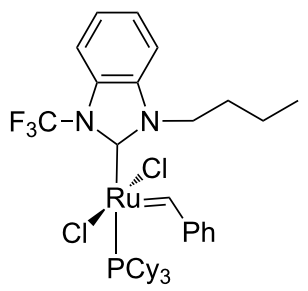

153

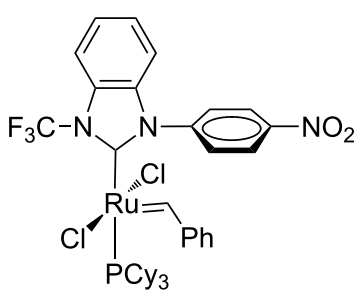

155
Figure 29: Grubbs-type complexes with $N$-trifluoromethyl benzimidazolidene NHCs 150-153, 155 and $\mathrm{N}$-isopropyl benzimidazolidene NHC 154.

The presence of one $\mathrm{N}$-trifluoromethyl substituent was supposed to impart positive effects on the catalytic performance, influencing both electronic and steric properties of the NHC ligand. Indeed, as already underlined, in symmetrical
NHC ruthenium complexes with fluorinated $N$-aryl groups previously reported by Grubbs, a Ru-F interaction was considered as responsible for the observed enhanced metathesis activity [15]. X-ray crystallographic analysis of complexes 150, 151 and 152 showed a $\mathrm{Ru}-\mathrm{F}$ interaction in the solid state. All the catalysts were tested in benchmark RCM and CM reactions, where they displayed no improved performances compared to the commercial GII-SIMes catalyst. On the other hand, they showed a remarkable chemoselectivity (up to 97\%) in the alternating copolymerization of norbornene (46) and cyclooctene (47). Moreover, in the ethenolysis of ethyl oleate (156, Scheme 13), they exhibited good selectivities (80-90\%) for the formation of desired terminal olefins 157 and 158.

Catalyst 154 containing an $N$-isopropyl group (Figure 29), which is considered to be sterically equivalent to the $N$-trifluoromethyl group, disclosed a substantially lower selectivity in both alternating copolymerization and ethenolysis reaction, underlining that the electronic effect determined by the strongly electron-withdrawing $\mathrm{CF}_{3}$ group and/or a $\mathrm{Ru}-\mathrm{F}$ interaction are the key factors for achieving a high selectivity in these transformations and, more general, could be used for modulating catalyst properties.

In another contribution by Coperet, Sigman and Togni, $\mathrm{N}-\mathrm{CF}_{3}$ complexes 150-155 (Figure 29) were tested for the ethenolysis of cyclic olefins to selectively form $\alpha, \omega$-dienes, along with other $23 \mathrm{Ru}$ benzylidene complexes featuring NHC ligands that differ in steric and electronic properties [50]. It is worth to underline that this transformation mediated by ruthenium initiators is less well investigated, presumably as a consequence of the high activity of ruthenium catalysts toward the competitive ROMP that is leading to low yields of terminal dienes. Among all the investigated systems, $N-\mathrm{CF}_{3}$ complex 153 emerged as the best performing catalyst in the ethenolysis of cis-cyclooctene (47), giving 96\% conversion of cyclooctene and 53\% selectivity for the ethenolysis product 161 (Scheme 14). Furthermore, catalyst 153 showed no detectable formation of poly(COE) (163) via ROMP in the absence of ethylene. On the

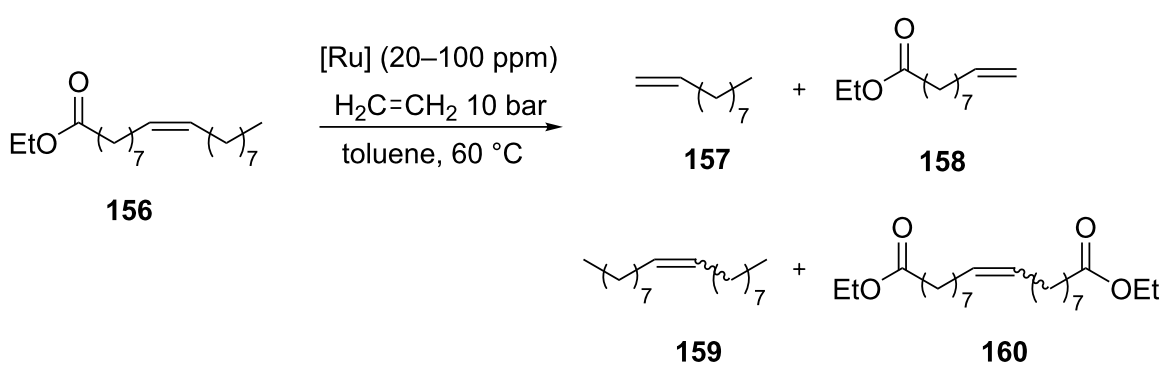

Scheme 13: Ethenolysis of ethyl oleate 156 


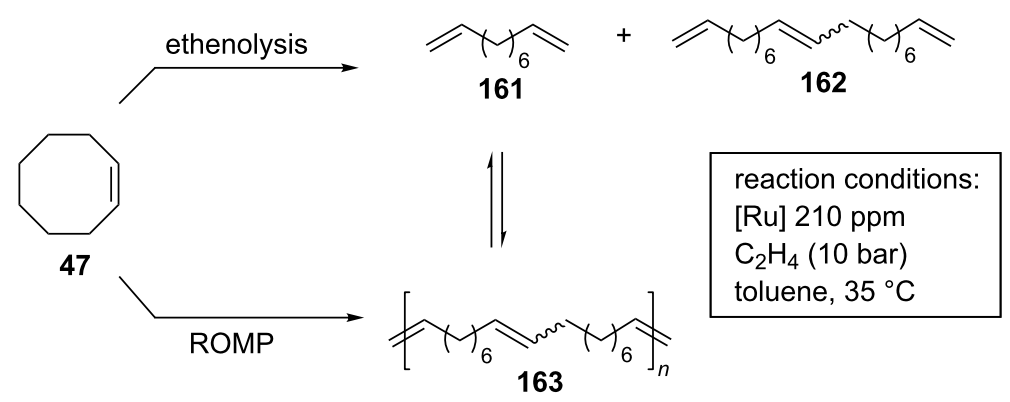

Scheme 14: Ethenolysis of cis-cyclooctene (47).

contrary, the benchmark catalyst GII-SIMes displayed only $12 \%$ selectivity for the desired product, giving predominantly poly(COE).

Due to its superior activity, complex $\mathbf{1 5 3}$ was also investigated in the ethenolysis of more challenging substrates such as norbornene derivatives, which typically are among the most popular ROMP monomers because of their high ring strain. The efficient synthesis of valuable functionalized $\alpha, \omega$-dienes was thus accomplished in useful yields $(>70 \%)$.

In order to explain the selectivity observed in the ethenolysis of cyclic olefins, steric and electronic descriptors of the NHC ligands obtained computationally were evaluated. The main role in controlling selectivity was ascribed to the $\pi$-acceptor ability of the NHC ligand that becomes more important with dissymmetric NHCs bearing an $\mathrm{N}-\mathrm{CF}_{3}$ group and drives the relative rate of degenerate metathesis and selectivity in ethenolysis of cyclic olefins.

\section{Ruthenium catalysts coordinated with backbone substituted $N$-alkyl, $N$ '-aryl NHCs}

Substitution at the backbone positions of the NHC framework has represented a remarkable advancement in the design of ruthenium olefin metathesis catalysts, due to the significant effects exerted on complexes' stability, reactivity and selectivity [51].

The first example of $C_{1}$-symmetric ruthenium catalyst bearing a backbone-substituted $N$-alkyl, $N^{\prime}$-aryl NHC ligand was reported by Collins et al. in 2007 (164, Figure 30) [52]. This complex represented an evolution of the chiral $C_{2}$-symmetric system previously proposed by Grubbs (165, Figure 30) [53], in which the replacement of the phenyl groups on the backbone with the more encumbered and electron-donating 1,2-di-tert-butyl units was made with the hope to enhance reactivity and enantioselectivity in Grubbs-type olefin metathesis catalysts. Moreover, in order to reduce the whole ligand's bulkiness which could have hampered attempts to prepare the catalyst, one of the $N$-aryl substituents was replaced with the smaller methyl group.

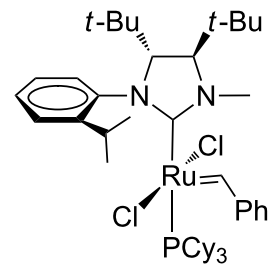

164

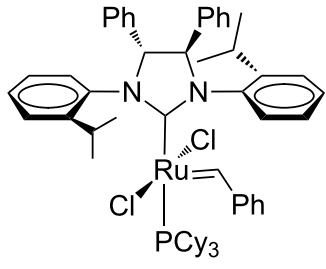

165
Figure 30: Grubbs-type $C_{1}$-symmetric (164) and $C_{2}$-symmetric (165) catalysts with a backbone-substituted NHC.

Complex 164 was obtained in poor yield (30\%) and characterized through NOE and X-ray analysis, revealing the exclusive formation of the rotational isomer in which the $N$-methyl lies over the carbene unit (the syn isomer, Figure 31).

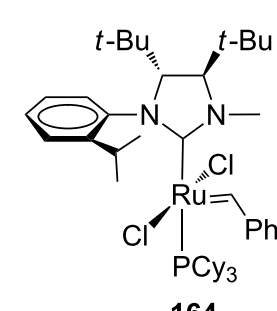

164 syn

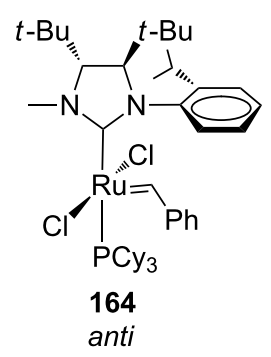

anti
Figure 31: Possible syn and anti rotational isomers of catalyst 164.

The catalytic performances of $\mathbf{1 6 4}$ were tested in the asymmetric ring-closing metathesis (ARCM) of prochiral trienes 166, 168 and 170 (Scheme 15, Table 6) [52,54] achieving enantiomeric excesses (ee) that were generally lower with respect to those obtained with the $C_{2}$-symmetrical analogue 165 [55] (Table 6). 
<smiles>CC=C(C)C(OCC)C(C)=CC</smiles>

$166 n=1$

$168 n=2$

$170 n=3$
$164(2.5-4 \mathrm{~mol} \%)$

$\mathrm{CH}_{2} \mathrm{Cl}_{2}$ or THF

$40{ }^{\circ} \mathrm{C}, 2$ or $3 \mathrm{~h}$ $0.055 \mathrm{M}$

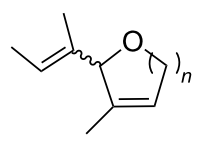

$167 n=1$

$169 n=2$

$171 n=3$
Scheme 15: ARCM of substrates 166, 168 and 170.

Table 6: ARCM of prochiral trienes 166,168 , and 170 promoted by catalysts 164 and 165.

\begin{tabular}{cccccc} 
entry & catalyst & substrate & additive & ee (\%) & conv $(\%)$ \\
\hline $1^{\mathrm{a}}$ & \multirow{2}{*}{164} & \multirow{2}{*}{166} & none & 82 & $>98$ \\
$2^{\mathrm{b}}$ & & & $\mathrm{NaBr}$ & 68 & $>98$ \\
$3^{\mathrm{b}}$ & & & $\mathrm{Nal}$ & 48 & $>98$ \\
$4^{\mathrm{a}}$ & \multirow{2}{*}{164} & \multirow{2}{*}{168} & $\mathrm{none}$ & 28 & $>98$ \\
$5^{\mathrm{b}}$ & & & $\mathrm{NaBr}$ & 34 & $>98$ \\
$6^{\mathrm{b}}$ & & & $\mathrm{Nal}$ & 42 & 41 \\
$7^{\mathrm{a}}$ & \multirow{2}{*}{164} & 170 & $\mathrm{none}$ & 60 & $>98$ \\
$8^{\mathrm{b}}$ & & & $\mathrm{NaBr}$ & 64 & 93 \\
$9^{\mathrm{b}}$ & & & $\mathrm{Nal}$ & - & - \\
$10^{\mathrm{a}}$ & $165^{\mathrm{c}}$ & 166 & none & 35 & $>98$ \\
$11^{\mathrm{b}}$ & & & $\mathrm{Nal}$ & 90 & $>98$ \\
$12^{\mathrm{b}}$ & $165^{\mathrm{c}}$ & 168 & $\mathrm{Nal}$ & 90 & $>98$ \\
$13^{\mathrm{b}}$ & $165^{\mathrm{c}}$ & 170 & $\mathrm{Nal}$ & 85 & 5 \\
\hline
\end{tabular}

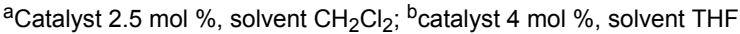
[54]; '[55].

The size of the ring formed was found to have a crucial influence on the enantioselectivity of the reaction with the enantiomeric excesses decreasing when passing from five to six and seven-membered rings (Table 6, entries 1, 4 and 7). The use of halide additives such as $\mathrm{NaBr}$ and $\mathrm{NaI}$ was also found to be dependent on the size of the ring formed, affecting both conversions and enantiomeric excesses with controversial results (Table 6). It should be underlined that the ambiguous halide influence constitutes a relevant difference between 164 and 165 . In fact, for the latter, the employment of halide additives had always a beneficial effect on the enantioselectivity [55].

The product ring size dependence observed in the desymmetrization of 166, 168 and 170 with 164 was explained considering that an NHC rotation is possible during the catalytic cycle and that 166, 168 and 170 should have different relative rates of cyclization. If the cyclization is slow, for instance in the case of seven-membered ring alkenes, an NHC rotation could occur during the catalytic cycle, thus determining a decrease of the enantiomeric excesses.
Rotation of the NHC ancillary ligand was detected in the case of 172, the Hoveyda-type analogue of 164 (Figure 32), for which a room temperature interconversion between syn and anti rotamers, observed at a ratio of 7.8:1, was revealed by NOE experiments. Surprisingly, despite such rotation the reactivity profiles and the enantioselectivities observed for 164 and 172 in the desymmetrization of $\mathbf{1 6 6}$ and $\mathbf{1 7 0}$ were comparable. This suggested that the reaction occurs faster when the $N$-methyl group is syn to the ruthenium-carbene than when the $N$-aryl group is located syn to the ruthenium-carbene moiety.

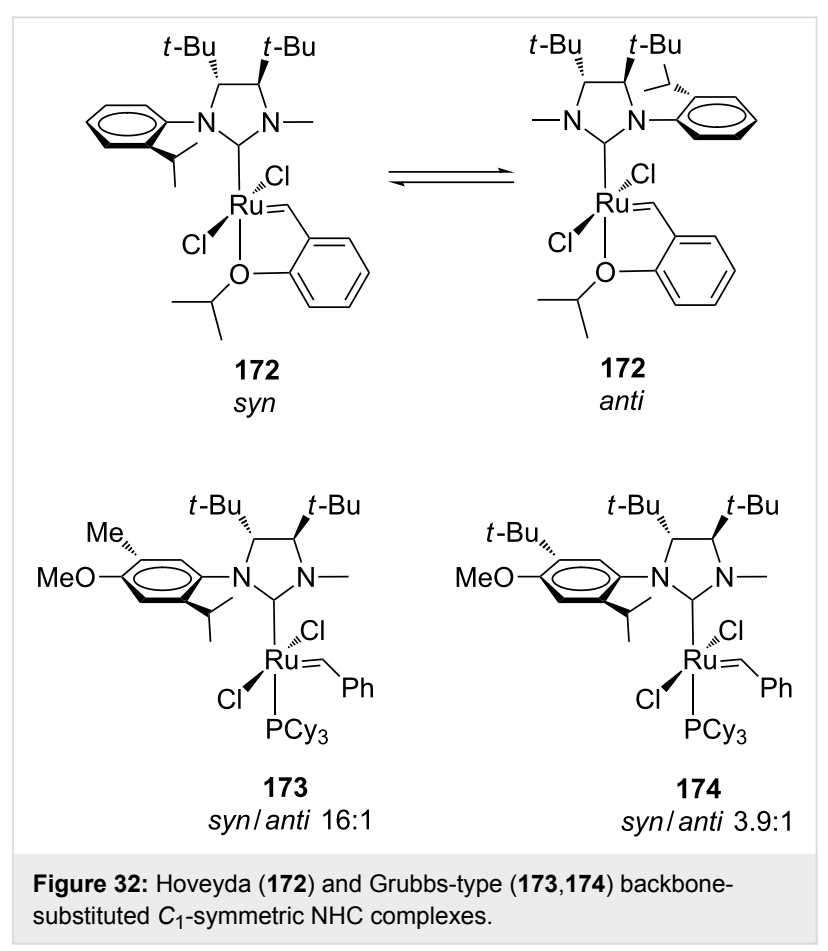

In order to try suppressing the NHC rotation during the catalytic cycle, catalysts 173 and $\mathbf{1 7 4}$, possessing additional substituents on the $N$-aryl group, were synthesized in moderate yields (42-44\%, Figure 32). Both complexes were isolated as a mixture of rotamers, with a prevalence of the syn isomer and no interconversion between the syn/anti rotational isomers was detected at room temperature [54]. The catalytic behaviors of 173 and 174 were tested in a series of model ARCM reactions and similar or improved performances with respect to 164 and 172 were noticed, suggesting that the significant reactivity could result from the major syn isomer.

It is noteworthy that complex $\mathbf{1 7 4}$ was found to be very competent also in cyclizations to form six and seven-membered ring olefins (175 and 177, Scheme 16), conversely to the other $C_{1}$-symmetric systems previously reported. On the other hand, coherently with 164 and 172, the best results were achieved without the use of any halide additive. 


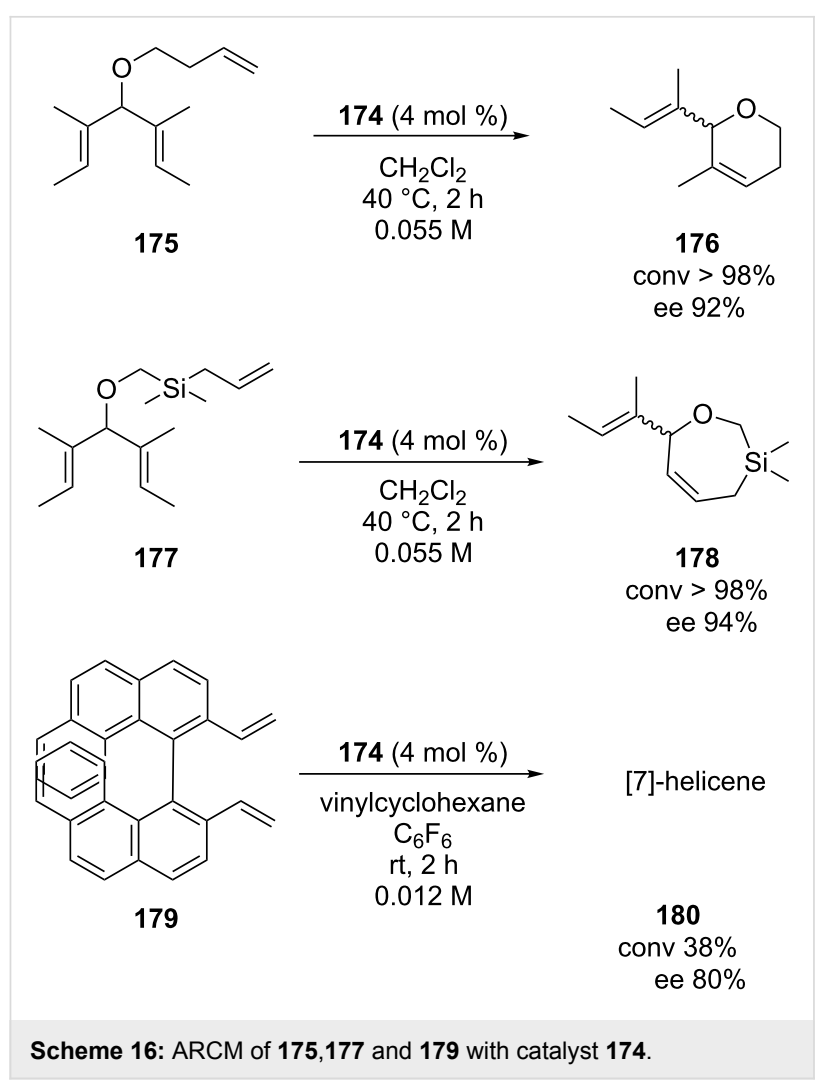

The unsymmetrical NHC catalysts 164, 173 and 174 were also examined in the asymmetric synthesis of [7]helicene (180). Among them, complex 174 exhibited the highest degree of selectivity, leading to the desired product with an enantiomeric excess of $80 \%$ [56]. An extension of this study, which examined the effect of the nature of the $\mathrm{N}$-alkyl group on the complexes' efficiencies, was published a few years later by the same group [57]. In this paper, new $C_{1}$-symmetric NHC ruthenium catalysts 181-184 bearing the more encumbered $N$-propyl or $N$-benzyl substituents were presented. All catalysts were obtained as a mixture of syn/anti rotational isomers (Figure 33).

The catalytic efficiency of these complexes was generally lower with respect to their $\mathrm{N}$-methyl analogues, both in terms of reactivity and enantioselectivity. However, despite this disadvantage, they showed an improved thermal and solution stability which allowed their application also in the ARCM forming tetrasubstituted alkenes, a reaction never examined so far with this family of complexes [58]. In particular, using a sample of catalyst 184 enriched in the anti rotational isomer (syn/anti 1:8), the hindered cycloolefins $\mathbf{1 8 6}$ and $\mathbf{1 8 8}$ were obtained with enantiomeric excesses of 71 and $78 \%$, respectively (Scheme 17).

More recently, Grisi and co-workers investigated new Grubbstype $C_{1}$-symmetric catalysts bearing methyl or cyclohexyl as the $\mathrm{N}$-alkyl group and two phenyl units in syn or anti relative

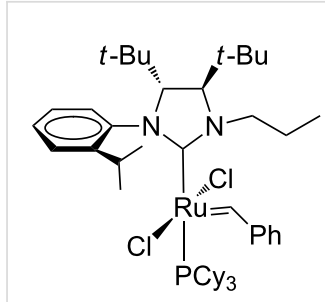

181

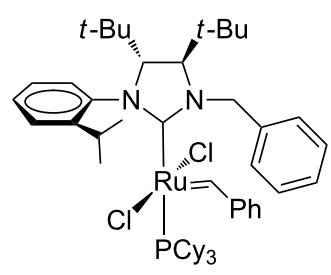

183

syn/anti $1: 1$ syn/anti > 95:5

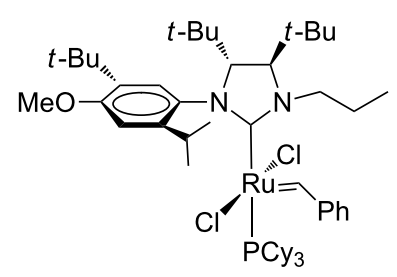

182

syn/anti 1:1.3

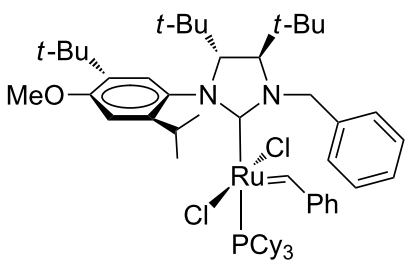

184

syn/anti 1:0.7
Figure 33: Grubbs-type $C_{1}$-symmetric NHC catalysts bearing $\mathrm{N}$-propyl $(181,182)$ or $N$-benzyl $(183,184)$ groups on the NHC.<smiles>C=C(C)COC(/C(C)=C\C)/C(C)=C\C</smiles>

185

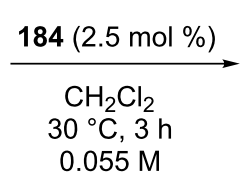

$0.055 \mathrm{M}$

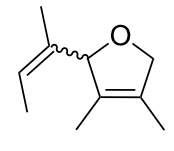

186

conv $50 \%$

ee $71 \%$<smiles>C=C(C)CCOC(C(C)=CC)C(C)=CC</smiles>

187

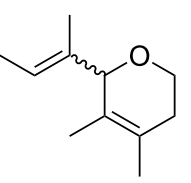

188

conv $>47 \%$

ee $78 \%$
Scheme 17: ARCM of 185 and 187 promoted by 184 to form the encumbered alkenes 186 and 188.

configuration on the backbone positions (189-192, Figure 34) $[59,60]$. These complexes were tested in several model RCM, ROMP and CM transformations and the size of the $\mathrm{N}$-alkyl group and the backbone configuration seemed to determine the different catalytic behaviors. The most significant reactivity differences between catalysts having syn or anti phenyl groups on the backbone were observed in the presence of an $\mathrm{N}$-cyclohexyl substituent. In particular, the $N$-cyclohexyl anti catalysts 192a and 192b showed high efficiencies in almost all tested metathesis transformations, especially in the most challenging 
$\mathrm{RCM}$ reactions of hindered diolefins in which they rival the commercial second generation Grubbs and Hoveyda-Grubbs catalysts. On the other hand, in the CM of 13 and $\mathbf{1 4}$ (Scheme 4), syn catalysts 191a and 191b gave the most interesting results, leading to the desired cross product $\mathbf{1 5}$ in a lower $E / Z$ ratio with respect to the anti congeners $192 \mathrm{a}$ and $192 \mathrm{~b}$ $(E / Z=3.6$ and 8.5 with 191a and 192a, respectively; $E / Z=2.6$ and 7.6 with $191 \mathrm{~b}$ and $192 \mathrm{~b}$, respectively).

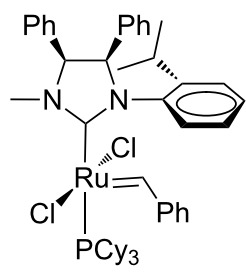

$189 a$

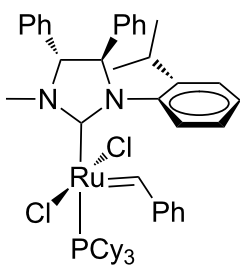

$190 a$

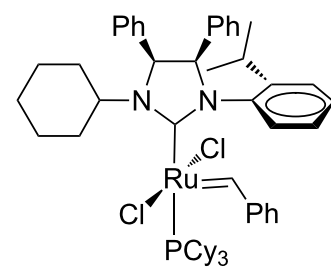

$191 \mathrm{a}$

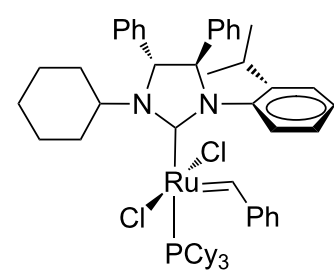

$192 a$

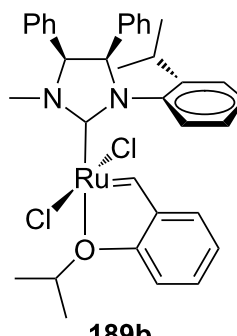

$189 b$

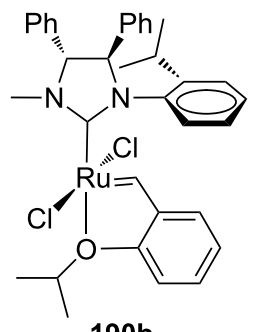

$190 b$

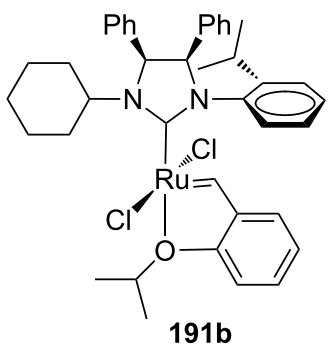

$191 b$

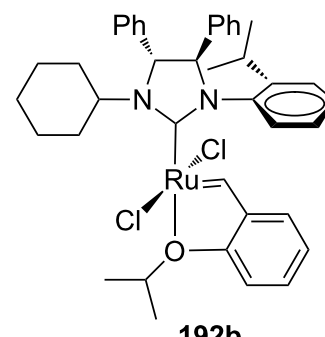

$192 b$
Figure 34: N-Alkyl, $N$ '-isopropylphenyl NHC ruthenium complexes with syn $(189,191)$ and anti $(190,192)$ phenyl groups on the backbone.

The effect of the NHC backbone configuration on the catalytic properties has been justified considering a more electron-donating nature of the anti ligand with respect to the syn ligand, as suggested by experimental and theoretical studies on the steric and electronic properties of $N$-cyclohexyl, $N$ '-isopropylphenyl
NHC ligands of 191 and 192 evaluated using the corresponding rhodium complexes [60].

A development of this study, which considered the utilization of other $N$-alkyl (neopentyl and neophyl) and $N$-aryl (mesityl) substituents, was published later [61]. Among these novel Hoveyda-type catalysts 193-198 (Figure 35), 198 was of particular interest due to its excellent thermal stability in solution and to the high efficiency in the ethenolysis of ethyl oleate (156, Scheme 13). In this reaction, performed under neat conditions at $50{ }^{\circ} \mathrm{C}$ and at a catalyst loading of $100 \mathrm{ppm}, 198$ gave up to $90 \%$ selectivity towards ethenolysis products $\mathbf{1 5 7}$ and $\mathbf{1 5 8}$ with a TON of 4400 . At a lower catalyst loading (20 ppm), the same catalyst showed $83 \%$ selectivity with a TON of 7500 , thus giving the best result reported up to now for ethenolysis reactions performed with $N$-alkyl, $N^{\prime}$-aryl NHC ruthenium catalysts.<smiles>CC(C)CN1C([R](Cl)=Cc2ccccc2OC(C)C)N(CC(C)(C)C)[C@H](c2ccccc2)[C@@]1(Cl)c1ccccc1</smiles>

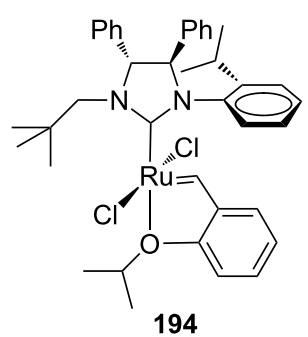<smiles>Cc1ccccc1C1C([R](Cl)(Cl)c2ccccc2)N(CC(C)(C)c2ccccc2)C(c2ccccc2)N1Cc1ccccc1OC(C)C</smiles><smiles>CC(C)Oc1ccccc1CN1C(c2ccccc2)C(c2ccccc2)N(CC(C)(C)c2ccccc2)C1[R](Cl)(Cl)c1ccccc1</smiles>

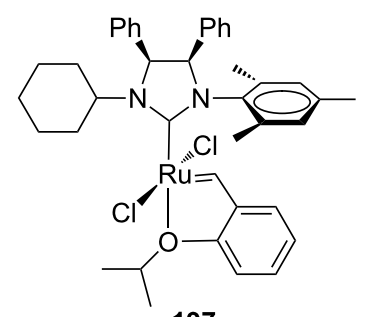

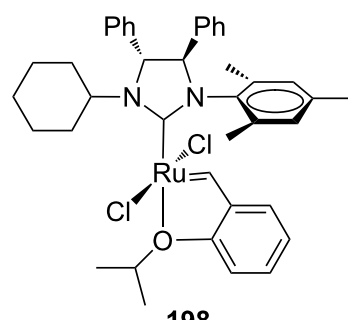

197

Figure 35: Hoveyda-type complexes 193-198 bearing $N$-alkyl, $N$ '-aryl backbone-substituted NHC ligands.

All the aforementioned catalysts with an anti NHC backbone configuration $(190,192,194,196$ and 198) were tested in model ARCM and AROCM reactions displaying moderate enantioselectivities $[60,61]$. In the ARCM of 166, differently from the other $C_{1}$-symmetric catalysts reported by Collins $[52,54]$, 
enantiomeric excesses were found to increase with the use of the halide additive. Interestingly, a pronounced efficiency towards the ring closing of the hindered alkene 199 was also observed (Scheme 18).<smiles>[R]C(=C)COC(/C(C)=C/C)/C(C)=C/C</smiles>

$199 \mathrm{R}=\mathrm{Me}$

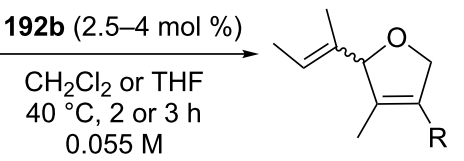

$167 \mathrm{R}=\mathrm{H}$

$$
\begin{array}{ll}
\text { conv }>98 \% & \text { ee } 19 \% \text { (no additive) } \\
\text { conv }>95 & \text { ee } 52 \% \text { (Nal) } \\
& 200 \mathrm{R}=\mathrm{Me} \\
\text { conv }>95 \% & \text { ee } 42 \% \text { (no additive) }
\end{array}
$$

Scheme 18: ARCM of 166 and 199 promoted by $192 \mathrm{~b}$
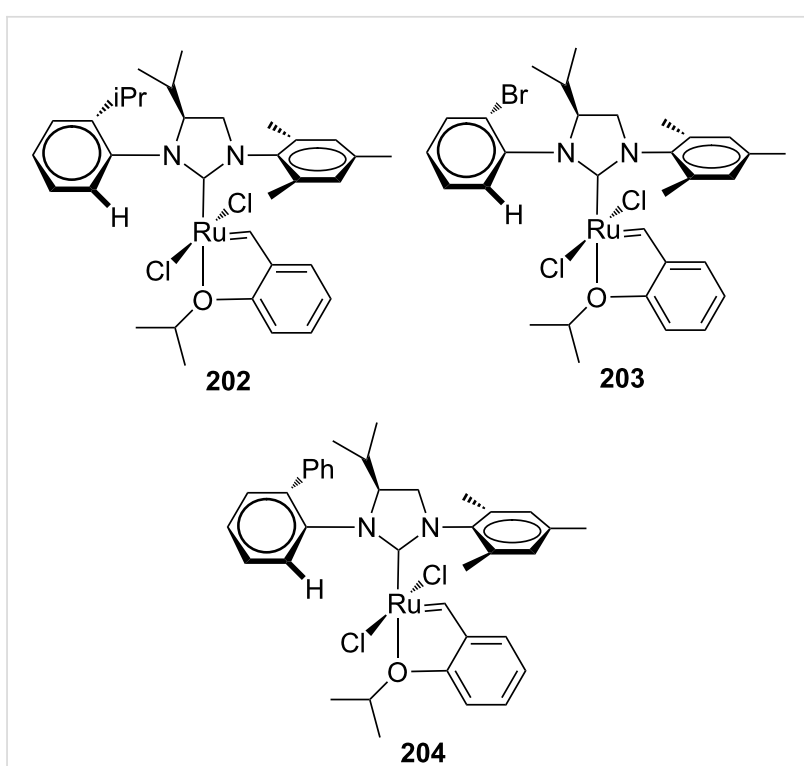

Figure 37: Backbone-monosubstituted catalysts 202-204.

The catalysts 202-204 were tested in model ARCM and AROCM reactions. In the latter transformation, they were found to be highly efficient showing both excellent enantioselectivity and $E$-selectivity. In the AROCM of $\mathbf{7 5}$ with styrene (Scheme 8, reaction performed at $-10{ }^{\circ} \mathrm{C}$ using 5 equiv styrene and $1 \mathrm{~mol} \%$ of the catalyst), complex 204 gave the desired product $\mathbf{7 6}$ in $>98 \%$ conversion, $93 \%$ ee and $E / Z$ ratio $>30: 1$.

Pursuing on this concept, the same group subsequently published novel chiral backbone-monosubstituted NHC complexes in which a bridge connecting the $N$-aryl group and the backbone unit makes aryl rotation no longer possible, thus creating a rigid environment in the surroundings of the alkene coordination sphere (205a,b, Figure 38) [64].
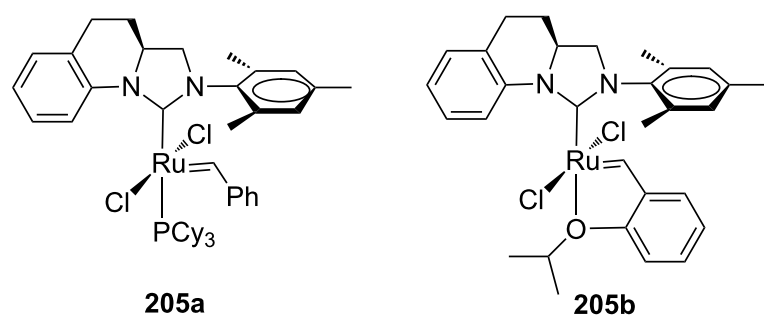

Figure 38: Grubbs (205a) and Hoveyda-type (205b) backbone-monosubstituted catalysts.

The performances of these catalysts in AROCM transformations were comparable with those of the congeners 202-204 albeit they showed a lower $E$-selectivity. These systems were successfully employed for the first time in the AROCM of $\mathbf{2 0 6}$ the flat mesityl segment as the other $N$-aryl subst
avoid steric hindrance reducing the reactivity. 
with allyltrimethylsilane. Indeed, using catalyst 205a, both $E$ and $Z$ geometric isomers of the desired cross product 207 were obtained in a high degree of enantioselectivity (Scheme 19).

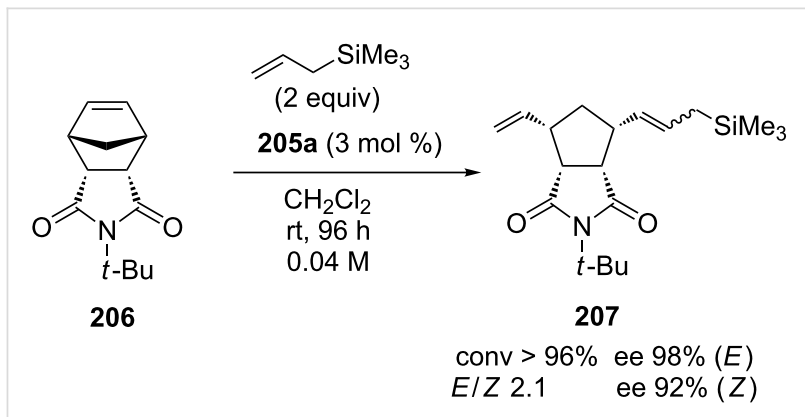

Scheme 19: AROCM of 206 with allyltrimethylsilane promoted by catalyst 205a.

\section{Conclusion}

In the last decades, a wide array of olefin metathesis ruthenium catalysts coordinated with monodentate unsymmetrical $\mathrm{N}$-heterocyclic diaminocarbene ligands have been developed. The introduction of this class of second generation catalysts, especially those containing alkyl, aryl substituted NHCs, has offered new opportunities for various metathesis applications, giving access, for instance, to highly selective alternating ringopening metathesis polymerization, ethenolysis reactions or self metathesis of $\alpha$-olefins. Both steric and electronic properties of the unsymmetrical NHCs appear to influence stability, activity and selectivity of the resulting ruthenium complexes. Therefore, the possibility to further modify the NHC ligand architectures creating new steric and electronic environments around the ruthenium center represents one of the most appealing topic on which research efforts should be focused. The development of tailor-made unsymmetrical NHC ruthenium systems is desirable to improve the efficiency in targeted metathesis reactions of not only academic but also industrial interest.

\section{Acknowledgements}

Financial support from the Ministero dell'Università e della Ricerca Scientifica e Tecnologica is gratefully acknowledged.

\section{ORCID ${ }^{\circledR}$ iDs}

Chiara Costabile - https://orcid.org/0000-0001-8538-7125

Fabia Grisi - https://orcid.org/0000-0003-3904-9541

\section{References}

1. Grubbs, R. H.; Wenzel, A. G.; O'Leary, D. J.; Khosravi, E. Handbook of Metathesis, 2nd ed.; Wiley-VCH: Weinheim, Germany, 2015. doi:10.1002/9783527674107

2. Grela, K., Ed. Olefin Metathesis Theory and Practice; Wiley \& Sons: Hoboken, NJ, 2014.
3. Vougioukalakis, G. C.; Grubbs, R. H. Chem. Rev. 2010, 110, 1746-1787. doi:10.1021/cr9002424

4. Samojłowicz, C.; Bieniek, M.; Grela, K. Chem. Rev. 2009, 109, 3708-3742. doi:10.1021/cr800524f

5. Tornatzky, J.; Kannenberg, A.; Blechert, S. Dalton Trans. 2012, 41, 8215-8225. doi:10.1039/c2dt30256j

6. Hamad, F. B.; Sun, T.; Xiao, S.; Verpoort, F. Coord. Chem. Rev. 2013, 257, 2274-2292. doi:10.1016/j.ccr.2013.04.015

7. Herbert, M. B.; Grubbs, R. H. Angew. Chem., Int. Ed. 2015, 54, 5018-5024. doi:10.1002/anie.201411588

8. Montgomery, T. P.; Johns, A. M.; Grubbs, R. H. Catalysts 2017, 7, 87. doi:10.3390/catal7030087

9. Ogba, O. M.; Warner, N. C.; O'Leary, D. J.; Grubbs, R. H. Chem. Soc. Rev. 2018, 47, 4510-4544. doi:10.1039/c8cs00027a

10. Vougioukalakis, G. C.; Grubbs, R. H. J. Am. Chem. Soc. 2008, 130 , 2234-2245. doi:10.1021/ja075849v

11. Lavallo, V.; Canac, Y.; Präsang, C.; Donnadieu, B.; Bertrand, G. Angew. Chem., Int. Ed. 2005, 44, 5705-5709. doi:10.1002/anie.200501841

12. Vehlow, K.; Gessler, S.; Blechert, S. Angew. Chem., Int. Ed. 2007, 46, 8082-8085. doi:10.1002/anie.200702560

13. Vougioukalakis, G. C.; Grubbs, R. H. Organometallics 2007, 26, 2469-2472. doi:10.1021/om0610593

14. Vougioukalakis, G. C.; Grubbs, R. H. Chem. - Eur. J. 2008, 14, 7545-7556. doi:10.1002/chem.200800470

15. Ritter, T.; Day, M. W.; Grubbs, R. H. J. Am. Chem. Soc. 2006, 128, 11768-11769. doi:10.1021/ja064091x

16. Masoud, S. M.; Mailyan, A. K.; Dorcet, V.; Roisnel, T.; Dixneuf, P. H.; Bruneau, C.; Osipov, S. N. Organometallics 2015, 34, 2305-2313. doi:10.1021/om501077w

17. Masoud, S. M.; Topchiy, M. A.; Peregudov, A. S.; Roisnel, T.; Dixneuf, P. H.; Bruneau, C.; Osipov, S. N. J. Fluorine Chem. 2017, 200, 66-76. doi:10.1016/j.jfluchem.2017.06.004

18. Karras, M.; Dąbrowski, M.; Pohl, R.; Rybáček, J.; Vacek, J.; Bednárová, L.; Grela, K.; Starý, I.; Stará, I. G.; Schmidt, B. Chem. - Eur. J. 2018, 24, 10994-10998. doi:10.1002/chem.201802786

19. Dinger, M. B.; Nieczypor, P.; Mol, J. C. Organometallics 2003, 22, 5291-5296. doi:10.1021/om034062k

20. Endo, K.; Grubbs, R. H. J. Am. Chem. Soc. 2011, 133, 8525-8527. doi:10.1021/ja202818v

21. Vehlow, K.; Maechling, S.; Blechert, S. Organometallics 2006, 25, 25-28. doi:10.1021/om0508233

22. Ledoux, N.; Allaert, B.; Pattyn, S.; Vander Mierde, H.; Vercaemst, C.; Verpoort, F. Chem. - Eur. J. 2006, 12, 4654-4661. doi:10.1002/chem.200600064

23. Ledoux, N.; Allaert, B.; Linden, A.; Van Der Voort, P.; Verpoort, F. Organometallics 2007, 26, 1052-1056. doi:10.1021/om060937u

24. Ledoux, N.; Linden, A.; Allaert, B.; Vander Mierde, H.; Verpoort, F. Adv. Synth. Catal. 2007, 349, 1692-1700. doi:10.1002/adsc.200700042

25. Yu, B.; Hamad, F. B.; Sels, B.; Van Hecke, K.; Verpoort, F. Dalton Trans. 2015, 44, 11835-11842. doi:10.1039/c5dt00967g

26. Vehlow, K.; Wang, D.; Buchmeiser, M. R.; Blechert, S. Angew. Chem., Int. Ed. 2008, 47, 2615-2618. doi:10.1002/anie.200704822

27. Lichtenheldt, M.; Wang, D.; Vehlow, K.; Reinhardt, I.; Kühnel, C.; Decker, U.; Blechert, S.; Buchmeiser, M. R. Chem. - Eur. J. 2009, 15, 9451-9457. doi:10.1002/chem.200900384

28. Vasiuta, R.; Stockert, A.; Plenio, H. Chem. Commun. 2018, 54 1706-1709. doi:10.1039/c7cc08476e 
29. Kavitake, S.; Samantaray, M. K.; Dehn, R.; Deuerlein, S.; Limbach, M.; Schachner, J. A.; Jeanneau, E.; Copéret, C.; Thieuleux, C. Dalton Trans. 2011, 40, 12443-12446. doi:10.1039/c1dt11643f

30. Stewart, I. C.; Keitz, B. K.; Kuhn, K. M.; Thomas, R. M.; Grubbs, R. H. J. Am. Chem. Soc. 2010, 132, 8534-8535. doi:10.1021/ja1029045

31. Thomas, R. M.; Keitz, B. K.; Champagne, T. M.; Grubbs, R. H. J. Am. Chem. Soc. 2011, 133, 7490-7496. doi:10.1021/ja200246e

32. Thomas, R. M.; Grubbs, R. H. Chem. N. Z. 2011, 75, 65-71.

33. Thomas, R. M.; Fedorov, A.; Keitz, B. K.; Grubbs, R. H. Organometallics 2011, 30, 6713-6717. doi:10.1021/om200911e

34. Rouen, M.; Borré, E.; Falivene, L.; Toupet, L.; Berthod, M.; Cavallo, L.; Olivier-Bourbigou, H.; Mauduit, M. Dalton Trans. 2014, 43, 7044-7049. doi:10.1039/c4dt00142g

35. Rouen, M.; Queval, P.; Borré, E.; Falivene, L.; Poater, A.; Berthod, M.; Hugues, F.; Cavallo, L.; Baslé, O.; Olivier-Bourbigou, H.; Mauduit, M. ACS Catal. 2016, 6, 7970-7976. doi:10.1021/acscatal.6b01428

36. Queval, P.; Jahier, C.; Rouen, M.; Artur, I.; Legeay, J.-C.; Falivene, L.; Toupet, L.; Crévisy, C.; Cavallo, L.; Baslé, O.; Mauduit, M. Angew. Chem., Int. Ed. 2013, 52, 14103-14107. doi:10.1002/anie.201308873

37. Fürstner, A.; Ackermann, L.; Gabor, B.; Goddard, R.; Lehmann, C. W.; Mynott, R.; Stelzer, F.; Thiel, O. R. Chem. - Eur. J. 2001, 7, 3236-3253. doi:10.1002/1521-3765(20010803)7:15<3236::aid-chem3236>3.0.co;2$\mathrm{s}$

38. Bielawski, C. W.; Benitez, D.; Grubbs, R. H. Science 2002, 297, 2041-2044. doi:10.1126/science.1075401

39. Bielawski, C. W.; Benitez, D.; Grubbs, R. H. J. Am. Chem. Soc. 2003, 125, 8424-8425. doi:10.1021/ja034524l

40. Prühs, S.; Lehmann, C. W.; Fürstner, A. Organometallics 2004, 23, 280-287. doi:10.1021/om0342006

41. Keitz, B. K.; Grubbs, R. H. Organometallics 2010, 29, 403-408. doi:10.1021/om900864r

42. Jong, H.; Patrick, B. O.; Fryzuk, M. D. Organometallics 2011, 30, 2333-2341. doi:10.1021/om2000844

43. Ablialimov, O.; Kędziorek, M.; Torborg, C.; Malińska, M.; Woźniak, K.; Grela, K. Organometallics 2012, 31, 7316-7319. doi:10.1021/om300783g

44. Ablialimov, O.; Kędziorek, M.; Malińska, M.; Woźniak, K.; Grela, K. Organometallics 2014, 33, 2160-2171. doi:10.1021/om4009197

45. Malinowska, M.; Kozlowska, M.; Hryniewicka, A.; Witkowski, S.; Morzycki, J. W. Monatsh. Chem. 2016, 147, 1091-1100. doi:10.1007/s00706-016-1697-7

46. Małecki, P.; Gajda, K.; Ablialimov, O.; Malińska, M.; Gajda, R.; Woźniak, K.; Kajetanowicz, A.; Grela, K. Organometallics 2017, 36, 2153-2166. doi:10.1021/acs.organomet.7b00211

47. Smoleń, M.; Kośnik, W.; Loska, R.; Gajda, R.; Malińska, M.; Woźniak, K.; Grela, K. RSC Adv. 2016, 6, 77013-77019. doi:10.1039/c6ra18210k

48. Grudzień, K.; Trzaskowski, B.; Smoleń, M.; Gajda, R.; Woźniak, K.; Grela, K. Dalton Trans. 2017, 46, 11790-11799. doi:10.1039/c7dt02180a

49. Engl, P. S.; Fedorov, A.; Copéret, C.; Togni, A. Organometallics 2016, 35, 887-893. doi:10.1021/acs.organomet.6b00028

50. Engl, P. S.; Santiago, C. B.; Gordon, C. P.; Liao, W.-C.; Fedorov, A.; Copéret, C.; Sigman, M. S.; Togni, A. J. Am. Chem. Soc. 2017, 139, 13117-13125. doi:10.1021/jacs.7b06947

51. Paradiso, V.; Costabile, C.; Grisi, F. Molecules 2016, 21, 117-136. doi:10.3390/molecules21010117
52. Fournier, P.-A.; Collins, S. K. Organometallics 2007, 26, 2945-2949. doi:10.1021/om700312c

53. Seiders, T. J.; Ward, D. W.; Grubbs, R. H. Org. Lett. 2001, 3, 3225-3228. doi:10.1021/ol0165692

54. Fournier, P.-A.; Savoie, J.; Stenne, B.; Bédard, M.; Grandbois, A.; Collins, S. K. Chem. - Eur. J. 2008, 14, 8690-8695. doi:10.1002/chem.200800642

55. Funk, T. W.; Berlin, J. M.; Grubbs, R. H. J. Am. Chem. Soc. 2006, 128, 1840-1846. doi:10.1021/ja055994d

56. Grandbois, A.; Collins, S. K. Chem. - Eur. J. 2008, 14, 9323-9329. doi:10.1002/chem.200801033

57. Savoie, J.; Stenne, B.; Collins, S. K. Adv. Synth. Catal. 2009, 351, 1826-1832. doi:10.1002/adsc.200900269

58. Stenne, B.; Timperio, J.; Savoie, J.; Dudding, T.; Collins, S. K. Org. Lett. 2010, 12, 2032-2035. doi:10.1021/ol100511d

59. Paradiso, V.; Bertolasi, V.; Grisi, F. Organometallics 2014, 33, 5932-5935. doi:10.1021/om500731k

60. Paradiso, V.; Bertolasi, V.; Costabile, C.; Grisi, F. Dalton Trans. 2016, 45, 561-571. doi:10.1039/c5dt03758a

61. Paradiso, V.; Bertolasi, V.; Costabile, C.; Caruso, T.; Dabrowski, M.; Grela, K.; Grisi, F. Organometallics 2017, 36, 3692-3708. doi:10.1021/acs.organomet.7b00488

62. Paradiso, V.; Menta, S.; Pierini, M.; Della Sala, G.; Ciogli, A.; Grisi, F. Catalysts 2016, 6, 177. doi:10.3390/catal6110177

63. Tiede, S.; Berger, A.; Schlesiger, D.; Rost, D.; Lühl, A.; Blechert, S. Angew. Chem., Int. Ed. 2010, 49, 3972-3975. doi:10.1002/anie.201000940

64. Kannenberg, A.; Rost, D.; Eibauer, S.; Tiede, S.; Blechert, S. Angew. Chem., Int. Ed. 2011, 50, 3299-3302. doi:10.1002/anie.201007673

\section{License and Terms}

This is an Open Access article under the terms of the Creative Commons Attribution License (http://creativecommons.org/licenses/by/4.0). Please note that the reuse, redistribution and reproduction in particular requires that the authors and source are credited.

The license is subject to the Beilstein Journal of Organic Chemistry terms and conditions:

(https://www.beilstein-journals.org/bjoc)

The definitive version of this article is the electronic one which can be found at: doi:10.3762/bjoc.14.292 